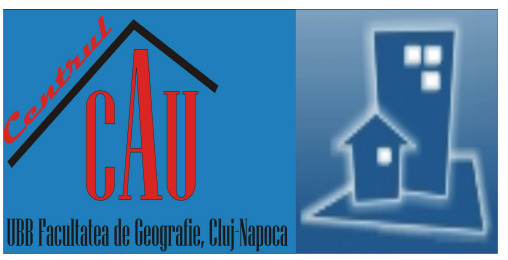

\title{
Urban Sprawl Costs: The Valuation of Households' Losses in Poland
}

\author{
Piotr LITYŃSKI ${ }^{1}$, Artur HOŁUJ1 \\ ${ }^{1}$ Kraków University of Economics, Faculty of Economy and Public Administration, Department of Regional Economics, Kraków, \\ POLAND \\ E-mail: litynskp@uek.krakow.pl, holuja@uek.krakow.pl \\ DOI: 10.24193/JSSP.2017.1.02 \\ https://doi.org/10.24193/JSSP.2017.1.02
}

K e y w o r d s: costs, loses, households, functional urban areas, urban sprawl, suburbanization

\begin{abstract}
A B S T RACT
The primary objective of the study is to estimate the financial losses incurred by households due to an intensification of chaotic suburbanization. The calculations include both annual losses and their forecast for 2030. The zone outside the Functional Urban Areas of regional capitals of Poland was considered for analysis. The results of the analysis indicate that, due to the chaotic suburbanization in Poland, social losses can be assessed as high as €4.1k per year. In 2030 losses could reach $€ 75 \mathrm{k}$ per household, of which €44k losses incurred directly, and $€_{35} \mathrm{k}$ represents the value of lost time. These losses are determined by the systemic shortcomings in Poland in terms of space management and road construction planning and implementation. Also, they results from the lack of effective implementation of spatial policy covering the area of the city and neighbouring municipalities. Thus it is crucial to introduce spatial plans covering the metropolitan area and further their effective implementation. In order to complete this challenge, a significant meaning is tied to a wide range of public social consultations which may be directed to fulfilling a spatial development vision and be one of social acceptance.
\end{abstract}

\section{INTRODUCTION}

Urban sprawl is defined as a process of decentralisation of population and employment in the city to a larger number of suburban communes and, simultaneously, controlled to very little extent by the regional land-use policy [24]. The term of urban sprawl is often associated with the phenomenon of suburbanization [32]. In Poland current suburbanisation can be perceived as a component of urban transformation processes identified with metropolitanisation. In this sense, it is a process aimed at establishing a new urban form referred to by authors as intercity, dispersed city, network city, and fuzzy structure. The economic consequences of the intensification of the processes of urban sprawl are currently in the early stages of diagnosis, especially in Poland [19]. As far as the costs incurred by the Polish self-government units and government are indicated only in selected studies [14], [15], [16], [27], whereas financial losses for households are not commonly and scientifically sufficiently exposed. It should also be noted that the urban sprawl in Poland is caused primarily by the location decisions of households [10], [11], and secondly, by the inefficiency of spatial policy.

The spatial planning system in Poland is characterized by three levels: government, regional and municipal. Each of these levels corresponds to specific planning documents: (1) National Spatial Development Concept; (2) Regional spatial development plan (their number is the same as the number of regions in Poland - 16); (3) Municipal study of conditions and directions of spatial development - there are 2,479 municipalities in Poland, Municipal spatial development plan - the 
number is unlimited, and administrative decisions such as: zoning approvals and ones determining the location of a public investment (number- unlimited). The spatial planning system in Poland continues to evolve.

During more than forty years of centrally planned economy, i.e. until 1989, major changes occurred in Polish space compared to Western Europe. However, these changes were most often the effect of a policy which was not based on the elementary and, by now, universal principles of sustainable development. Moreover, the socio-economic policy did not seek in a broader context for the implementation of its guidelines in light of the widely understood spatial order. Lack of coordination of activities in respect to spatial management at the local level led to increasing chaos that persists in many places in Poland to this day. Despite the fact that problems related to spatial development have been properly recognized by the public authorities for over 20 years, the quality of Polish space is still not satisfactory [13].

As De Vos and Witlox (2013) point out, urban sprawl can be considered from a micro-economic approach [5]. According to micro-economic location theories, households trade off transportation costs and land prices in order to find their ideal residential location, whereby living close to a city centre is characterised by high land prices and low transportation costs and living farther away from a city centre with low land prices and high transportation costs. But, there are studies [4], [31] claiming that travel costs play a role in residential location choice. There are also studies which criticize these theories since they overemphasize the importance of travel costs [7], [23], [33].

Developments in technology - making transportation improvements possible - and investments in transportation infrastructure have reduced travel costs (transportation became faster and cheaper) making land prices more important in residential location choices, resulting in households choosing to live in remote areas with low land prices. This explains why faster and cheaper transportation has not resulted in reduced travel times and reduced expenditures of households on travel [8], [21], [26].

Considering the above, the primary objective of the present study is to estimate the losses that are incurred by households due to intensification in the chaotic process of suburbanization. The supplementary aim is also to present a set of results in the convention acceptable for households making a decision on the location within the suburbs. In the light of the analyzed literature, the financial losses incurred by households are focused primarily on the costs of travel to the city, for the following purposes: professional, educational, shopping, etc. [17].

Therefore, in the present study, as a loss for the residents of suburbs, the oversized costs of travel to the city were taken into account. The estimates represent an annual amount of actually incurred financial losses and the value of lost time. Additionally we attempt to estimate the amount in the projection horizon of 2030.

The territorial scope of the analysis is the Functional Urban Areas of Regional Capitals (FUA) that have been operationalized by P. Śleszyński [30] for the purpose of KPZK 2030.

The Functional Urban Areas are related to a metropolization processes and affected by the processes of chaotic urbanization. It is because delimitation of FUA includes, amongst others, selected morphological indicators (population density in areas excluding forests and bodies of water, dwellings commissioned for use), but functional (registered residence, commutes to employment in the FUA core).

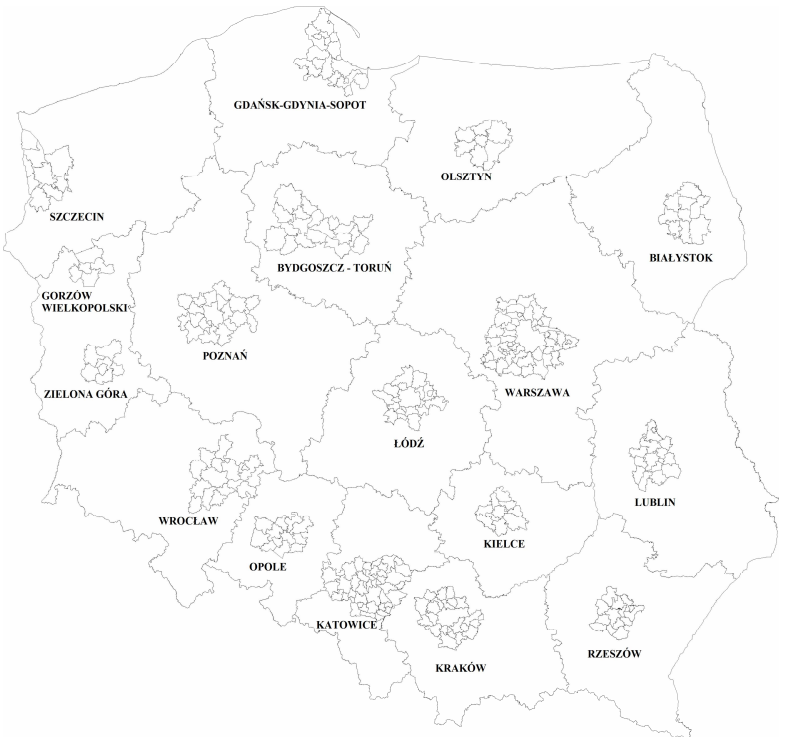

Fig. 1. Study area - the functional urban areas in Poland (source: own elaboration).

Based on the research results of Lityński (2015), chaotic suburbanization in the FUA can be characterized as suburbia with the deficiency in clustering of housing in settlements [18].

Housing is freely and randomly located in the study area. There is often a lack of continuity of spatial development, i.e. leapfrog combined with a relatively low density of houses. These residences, however, are not very dispersed, but rather grouped. In some FUA the sprawl is characterized by two features.

The first one is the lack of centralization, which means the housing development is located relatively far from the city core. The second feature is the lack of concentration of housing, which means houses are scattered throughout the area, especially along roads. According to Brańka [2] FUA in Poland differ in terms of socio-economic development. The best development situation is attributed to FUA of Poznań and Warsaw. In the weakest condition are the urban areas of the socalled Polish Eastern Wall. 


\section{THE BACKGROUND FOR RESEARCH ON THE COSTS OF URBAN SPRAWL}

In the article, losses due to urban sprawl are recognized as a financial loss in commuting to the city core incurred by households. The losses have been estimated as the sum of two categories, i.e.: financial losses incurred directly and the value of time lost. Amounts presented in Euro are resulting from the conversion from PLN by the average exchange rate of the PLN to the Euro as a basis for converting the value of public procurement [ $€ 1=$ PLN 4.1749]. In addition, the necessary reflection requires two basic assumptions taken in the analysis in relation to the categories of losses and household:

The first explanation refers to the relationship between "loss" vs. "costs". It is assumed that the losses are a narrower category than the notion of cost. Presented estimates include only those for the losses that result from living in the suburbs. In other words, if these same households were located in a city, such expenditure would be nonexistent. Such recognized losses in the literature are close to the term of net costs of urban sprawl [3], [9], [17], [22], [32]. In light of the literature, the net costs include those from additional expenditure of households, which arose due to the location of new households in the area of suburbs. These expenses relate to both migrants and indigenous inhabitants of the suburbs. At the same time it should be noted that a significant loss of living in suburbs is commuting to work - both wasted time and direct expenses (broader - [29]). In addition, according to Wassmer [32] due to the postponement in time, the costs in commuting are taken into account insufficiently at the time of making the decision of locating one selves' home in the suburbs. Also, it should be noted that in the literature, an increased expenditure on the purchase of a house was not catalogued among the losses. Explanations of the lack of this expenditure category may be found in microeconomic theory, in particular the theory of consumer's decision [1]. Microeconomic interpretations indicate that households maximize their utility having regard to its budgetary constraints. In this light, households will allocate for the purchase of a house in the suburbs of the same amount as the purchase of an apartment in the city. The limiting factor of expenditure is the financial capacity of the household, while the factor determining the choice of location is a utility in the objective sense (e.g. the cost of $1 \mathrm{~m}^{2}$ ) as well as subjective (e.g. contentment).

The second assumption refers to the methodical operationalization of the category of a household. For the attainment of the range of conducted estimates, available statistics (LDB, CSO) did not cover the analytical needs in terms of households. Therefore, the calculation used a feature "the number of housing" instead of households. The rationale for the conversion is the convergence of these definitional categories, i.e. households are defined as: a person or group, living together or separately, with mutual financial support; this is also single person, financially independent. Honouring this definition, there are noticeable convergence characteristics: number of housing and the number of households.

\subsection{Losses incurred directly}

Losses incurred directly have been calculated as an annual financial loss incurred by households due to commute and the return from the city core by: (a) own car, (b) public transport. Estimation of losses (a) for travelling by car included the following algorithm:

1). Calculation of daily distance to and from the city $[\mathrm{km}]$. This distance is the ratio of the number of cars in the municipality and the distance between the municipal centre and the border of the city core. The ratio reflects the daily distance incurred by households of the municipality. The number of cars in the municipality was a division of data concerning the number of vehicles in the region through the participation of the population. Distance measurement was made on the basis of actual streets using Google Maps and taking into account congestion in both directions. Congestion hours adopted as 7:30-8:45 and 16:30-18:00 [12].

2). Calculation of daily car trip losses [€]. Calculated in (1) daily distance is multiplied by the applicable depreciation rate for $1 \mathrm{~km}$ travelled by car with an engine capacity exceeding $900 \mathrm{~cm}^{3}$ (0.8358 PLN; [25]). The ratio captures the daily losses of households of the municipality for the trips.

3). Annual losses due to car trips [€]. Calculated in (2) daily losses were the basis for multiplying by the number of working days in a year.

Estimation of losses (b) in respect to trips by public transport the following algorithm was used:

1). Calculation of the number of households that use public transport in the municipality of [one.]. The calculations assume a constant for all the analyzed municipalities in a utilization rate of public transport at $30 \%$. The level of the indicator was established on the basis of the results presented in separate studies, i.e., according to research [6], [16] 36\% of use in commuting from the suburbs is by means other than a car; and developing by Lityński and Hołuj (2015) the corresponding rate is $21 \%$ [20]. Thus, the assumed value of the indicator use of public transport (30\%) has become a multiplier of the number of dwellings in the municipality, which was to give the number of households in the municipality of using public transport.

2). Calculation of daily losses due to commuting by public transport [€]. Calculated in (1) the number of households using public transport was 
multiplied by the difference of the ticket price from the municipality to the city centre and the ticket price in the city. The ratio is multiplied by 2 , which reflects the loss in commuting both ways.

3). Annual losses due to commuting by public transport [€]. Calculated in (2) daily losses were the basis by multiplying the number of working days in a year.

\subsection{The value of time lost}

Estimates of the value of time lost were calculated - as above - as losses incurred by households for commuting by (a) own car, (b) public transport. Estimation of value losses (a) due to loss of time in respect to commuting by private car included the following algorithm:

1). Calculation of the daily loss of time for travel to and from the city [min.]. The loss of time is the ratio of the number of cars in the municipality and the travel time between the municipality centre and the border of the city core. The ratio shows the daily losses of time incurred by households in the municipality. Time measurement was made on the basis of the actual time of travel by car through streets in both directions, including congestion (hr. 7:30-8:45, and hr. 16:3018:00). To measure time, specific features of Google Maps were used.

2). The calculation of the daily loss of time driving a car [€]. Calculated in (1) daily loss of time they have been converted to hours and multiplied by the average hourly wage in the county.

3 ). The annual loss of time due to commuting by car [€]. Calculated in (2) daily losses were the basis by multiplying the number of working days in a year.

Estimation of value losses of (b) lost time with regard to travel by public transport included the following algorithm:

1). Calculation of the daily loss of time due to commuting by public transport [min]. The previously calculated number of households using public transport was the multiplier of travel time in both directions. To calculate the travel time of public transport it were used features of Google Maps reflecting the real travel time of public transport - including congestion, i.e. hours 7:30-8:45 and hours 16:30-18:00.

2). The annual value of loss on the public transport commuting [€]. Calculated in (1.) daily loss expressed in hours, which was the basis for the multiplication by the average hourly wage in the county and the number of working days in a year.

\subsection{The projection of loss value}

The estimates in respect to losses allowed for taking an attempt to prepare financial projections. The time horizon of projection coinciding with the national spatial strategy [15] was implemented. The projection was prepared in the same system as discussed in the annual estimates, i.e. in division into direct financial losses incurred by households and the value of time lost. The sum of the two accounted for expected losses associated with commuting. Among the most important adopted assumptions, is that the projection will show values at current gross prices, other factors will be unchangeable. So, the projection includes forecasted dynamics in prices of consumption goods and services as well as the growth of wages. But the projection also assumes that in the analyzed area the number of households and road system will not change.

The projection of loss directly incurred by households for commuting in both directions to the city core was calculated as follows:

1). The annual losses incurred by households estimated in II.1., annually adjusted for the rate of projected growth of prices of consumer goods and services (CPI). Projected value of the CPI for the period until 2030 was obtained from the current government document concerning to the guidance on macroeconomic assumptions for the purpose of longterm financial forecasts [34].

2). The projection of losses calculated in (1.) extended by losses from the purchase of an additional car, which gives a total estimation of loss incurred directly from commuting to the city. For estimates of loss related to periodically purchasing a car, three key assumptions were adopted: (a.) In the period from 2017 to 2030 every household will buy a car twice; (b.) The purchase price of the car is $€ 12 \mathrm{k}$, but to the calculation was adopted to €6kdue to the sale of the previous car. Both, the frequency and the value of the purchased vehicle, were based on the results of separate studies [20]; (c.) Loss in buying a car is a loss resulting from the need to purchase an "additional" vehicle. An "additional" vehicle is estimated as the difference between the average number of cars per household in the city core (pattern) and the average number of cars per household in the analyzed municipality.

However, the projection of the value of time lost by households on commuting was calculated as the ratio of the annual value of time lost for commuting incurred by households (previous estimated) and the projected wage growth. Forecast of the dynamics of wage for the period ending 2030 was obtained from the current government document concerning to the guidance on macroeconomic assumptions for the purpose of long-term financial forecasts [34].

\section{THE RESULTS AND DISCUSION}

Table 1 presents the amount of annual loss for commuting to and from the city core in the FUA. Table 1 therefore includes the value of the losses incurred by all households in a particular FUA, and the average 
value for a single household the FUA. In terms of an average household located in the outer zone of FUA, losses are high, because the amount of $€ 2$.4k per year of directly incurred losses, and $€ 1.7 \mathrm{k}$ of the loss of time; which is the total value of $€ 4.1 \mathrm{k}$ losses. Table 1 is also the projection of losses in the period 2017 to 2030 on which households located in the outer zone of FUA are exposed. An average household due to the location of suburbia will sustain losses in the amount close to the cost of purchasing, i.e. an apartment. The amount of expected losses for that household is $€ 75 \mathrm{k}$, which consists of: $€ 44 \mathrm{k}$ directly incurred losses and $€_{35 \mathrm{k}}$ losses due to lost time.

Table. 1. Annual losses and the projections of losses on commuting to and from the city in the FUA.

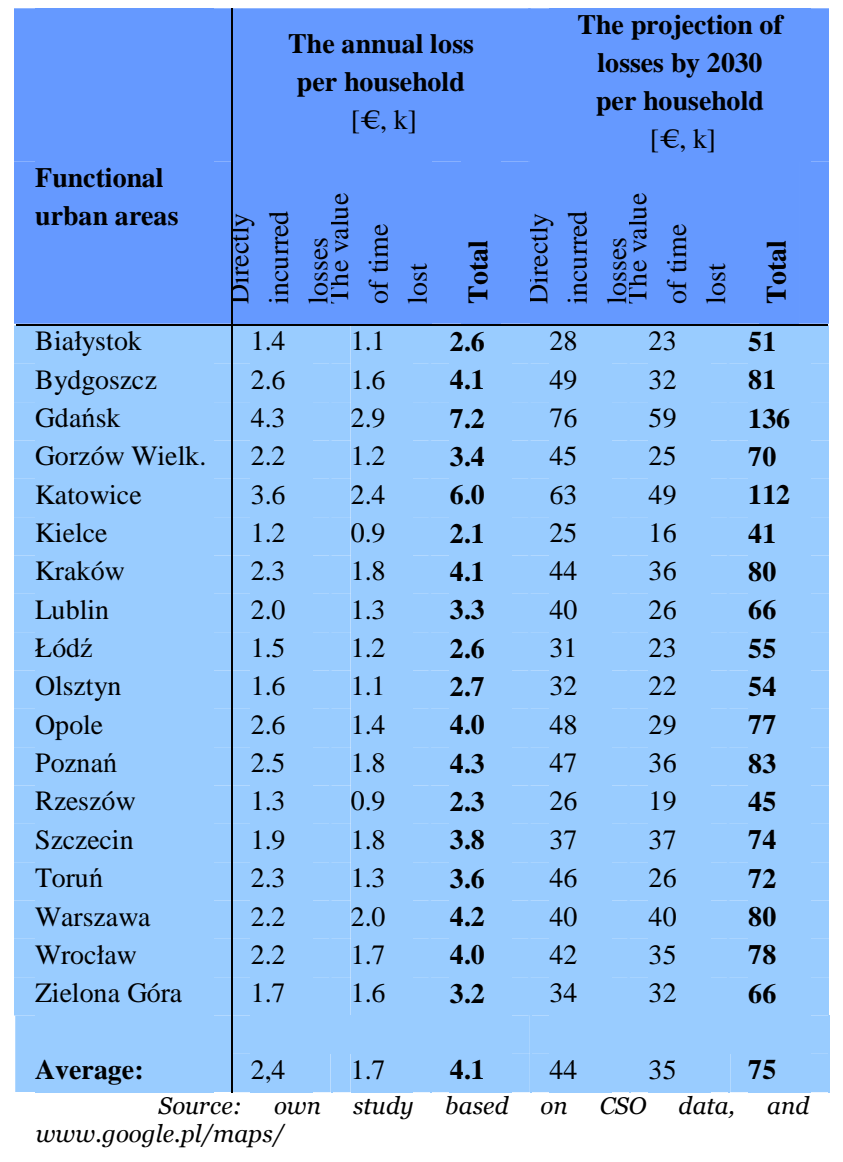

In the Appendix of the study (see Appendix 1), there are presented estimates calculated for households in specific municipalities belonging to the outer zone of FUA. That is, each municipality is represented by the value per single household and the value to the society of the entire municipality. The way of presenting the maps in the Appendix includes:

- Fig. 1 and Fig. 2 - that is, the losses incurred directly, i.e. Fig. 1 shows annual losses; and Fig. 2 is a projection for 2030, that single households will probably experience.

- Fig. 3 and Fig. 4 - that is, the value of lost time, i.e. Fig. 3 indicates the annual value of time lost for travel to/from a city; whilst Fig. 4 is a projection for 2030 similar losses.

- Fig. 5 and Fig. 6 - reveal the sum of direct losses and the value of time lost; i.e. Fig. 5 indicates total annual losses; and Fig. 6 is a projection for 2030 aggregated losses

The results presented in the Appendix allow for the identification of potential losses to the household of a specific municipality or decision-maker on the location in the municipality. The financial losses for households in Poland indicated in Appendix are a consequence of systemic deficiencies in spatial management, which are also causing discontent in society. Apart from additional financial resources, living in the FUA in Poland also requires the ability to adapt to chaotic changes in space. As a result of various factors, there is a process of development of free areas (usually agricultural areas) by housing. This situation is not fully controlled by spatial policy, the phenomena incurs the losses of all users of the area. In order to reduce negative economic phenomena, it seems necessary to firstly design sensibly and then implement solutions for linear infrastructure (roads). This is a very difficult issue in Poland due to the complexity of the procedure and the scope of impact. It is undeniable to state that there is a relationship between the development of FUA (i.e. economic and social) and the quality and availability of technical infrastructure.

As a rule, the surplus of infrastructure should be sought, but due to the financial condition of many local governments in Poland, investment often involves delayed projects in order to eliminate the congestion. In extreme circumstances one can note a situation in which it is assumed that the construction of new road infrastructure (i.e. bypasses) will be a stimulant in the development of entrepreneurship or in the creation of new housing areas. It can be assumed that in many cases this will be true. However, without the relevant research at the design stage, the investment may involve a long-term capital freeze, and the intended potential effectiveness will never be achieved.

In addition, there are often issues with the matter of the design of the road itself especially when it is to run through attractive natural and agricultural landscapes. The appreciated good is the landscape itself, whose protection is difficult to argue in Poland. First, it is very difficult to identify and appreciate landscape values, and secondly, in spite of this year's recompilation of polish law, its execution may be very difficult to achieve. The lack of understanding and involvement of local communities in project procedures and the seemingly balanced spatial policy in Polish municipalities are also often a problem. Local authorities sometimes resort to designing road infrastructure solutions based on specs, which is not always an antidote to the creation of new, qualitatively desirable infrastructural solutions. This is a path of 
practice that in fact frees investors from the assumptions of spatial policy and the negative voices of the people.

It is relatively difficult to designate a universal method of equipping a territorial unit with road infrastructure. It is also important to point out the time horizon and expenses resulting from the spatial and urban planning process itself. Time-consumption is closely linked to multi-faceted preparation of space for the intended investment and its implementation. The elaboration and subsequent implementation of the documents necessary in the light of the rules in Poland, requires a fair course of action, understood as a common effort (officials, designers, counsellors, investors and residents) to meet the needs of all concerned, especially local communities. Definitely articulated justice is often perceived incorrectly, but its absence, as in the short term, is likely to cause conflict in the developed space in the long run.

Partialism in investment design is justified when social participation in the investment process is equally and mutually respected. The ambition to meet the needs of only selected communities can cause a chain reaction, which will cause a long-term distribution of residents into more and less privileged. The methodology should be correlated with the key documents in the discussed process, including in particular: the study of conditions and directions of spatial planning and the local spatial development plans of the municipality as well as the evaluation of the environmental impact and the project itself. Thus as most essential is the substantive quality of these studies.

In parallel a reference needs to be made to the economic conditions of Poland. They are among the most important factors limiting the development of road infrastructure, whose deficiencies generate the discussed costs. In spite of the implemented European Union regional policy, the quality of the natural environment or the benefits of the road investment are still under way - there is a lack of a broad assessment of the economic viability of investments, especially in rural areas.

Local roads, which in the analyzed case are relevant, should be patrolled to link the suburbs to the core city of FUA. A direct route through the municipality or using a liaison connecting road is of necessity. In the case of roads with are not local, terracing is acceptable in omitting villages which stand in its way.

The road design discussions must also address the widely understood investment costs, including real estate redemption, design and construction work, operational and environmental costs. The intensity of traffic affects the rate of return on road construction, so for those with low traffic, the selection and preparation of land for such a construction needs to be done in a cost efficient matter. On the other hand, it is undeniable that the investment in infrastructure is necessary because in the overall settlement it limits the cost of mobility. Natural conditions should also be used, especially in the formation of bland, which may considerably reduce investment costs. In addition, the roads serving small towns should be designed to be used in a way to fulfil as much locally-available potential as possible, without creating unnecessary pressure on residents (for example, through unintended terrains, too wide a lane etc.).

The impact of design and planning issues with local communities is a difficult challenge for decisionmakers. The participation of many actors in a broadly understood planning and design process should consist in maximizing the information and involvement of citizens in the intended and subsequently conducted activities in space. This is difficult to implement because local authorities are not always aware of local potential that will be identified in the same way by local communities - resulting in multiplier effects and rising costs and losses. This problem is related to the need to establish a comprehensive information system and educate the society about space management, requirements of spatial order or operation in accordance with the principles of sustainable development. Unfortunately, the inhabitants, especially small settlements, often do not participate actively in the life of the community. The phenomenon involving more residents is a potential "threat" consisting, for example, of seizing property for road construction, sidewalks, sewage networks, etc. In addition, the spatial planning system in Poland is ineffective which causes urban sprawl. The lowly controlled sprawl of development without the relevant primary regulations on locating road infrastructure generates a limited mobility in the FUA. This limitation is a direct consequence of the financial loss of a single household resulting from the necessity of travelling due to the needs of existence.

\section{CONCLUSIONS}

In the article, the subject of the analysis was losses on commuting and returning from the core city, and the area of analysis was those affected by the phenomenon of urban sprawl in Poland. The financial losses of a single household resulting from the need to move within the urban areas were calculated. Detailed information on the amount of incurred and projected loss by households is presented in the annexes describing the conditions prevailing in individual areas in Poland.

The losses that households are facing due to the chaotic suburbanization in Poland can be assessed as high. These losses relate to all residents of suburbs. Intensification of the process of chaotic suburbanization 
has financial consequences not only for the migrants but also the indigenous people, e.g. by extending the time of travel and related costs. These estimates should also be taken into account by families who decide to move to the suburbs. A perspective of losses on average $€_{75 \mathrm{k}}$ within the 14-years, could materially affect the location decision. From the point of view of macroeconomic development prospect of the country, both categories of losses are important. Increasingly, in fact, are the aspirations of local government units to finance the development through internal sources. In this category of sources, aside from funds of local government, these funds are also of individuals and households. Thus, the losses directly incurred by households ( $€ 44 \mathrm{k}$ per household) reflect the potential loss for development funds. These losses are due to systemic shortcomings in Poland in terms of space management and road construction planning and implementation.

In Poland, the development of space in urban and metropolitan areas is not fully controlled by the existing spatial policy. There is no effective implementation of spatial policy covering the area of the city and neighbouring municipalities. This results in high costs for all users of the area. In order to reduce negative economic phenomena, it is necessary to design and implement a coherent road infrastructure solution for the city and surrounding municipalities. However, such solution encountered obstacles in their financing such as high cost of living, cooperation between municipal authorities, social conflicts of residents. The spatial plans that go beyond the territorial scope of one municipality may play an important role in overcoming obstacles.

These plans must be widely consulted in society and be a coherent vision of the authority of many municipalities. Such consultation will only be effective if it is not only the implementation of statutory necessity, but rather will be seen as an appropriate tool for spatial and socio-economic development.

\section{REFERENCES}

[1] Begg, D., Fischer, S., Dornbusch, R. (2007), Microeconomics, Polish Economic Publishing House, Warsaw.

[2] Brańka, P. (2016), The level of socio-economic development of the Cracow Metropolitan Area against selected metropolitan areas in Poland, [in:] A. Noworól, A. Hołuj (eds.): Socio-economic changes in suburban areas of cities. Case study of the Cracow Metropolitan Area. Warsaw, CeDeWu.

[3] Brueckner, J. K. (2000), Urban Sprawl: Diagnosis and Remedies, In: International Regional Science Review, no. 23.

[4] Clark, W. A. V., Huang, Y., Withers, S. (2003), Does commuting distance matter? Commuting tolerance and residential change, In: Regional Science and Urban Economics, 33 (2).

[5] De Vos, J., Witlox, F. (2013), Transportation policy as spatial planning tool; reducing urban sprawl by increasing travel costs and clustering infrastructure and public transportation, In: Journal of Transport Geography, 33 .

[6] Commuting to work in Poland based on LFS (2011), Central Statistical Office, Department of Labor Market.

[7] Giuliano, G. (1989), New directions for understanding transportation and land use, Environment and Planning A, 21 (2).

[8] Glaeser, E., Kohlhase, J. E. (2004), Cities, regions and the decline of transports costs, In: Regional Science, 83(1).

[9] Gordon, P., Richardson, H. (1996), Employment Decentralization in U.S. Metropolitan Areas: Is Los Angeles an Outlieror the Norm?, Environment and Planning Association, no 28.

[10] Hołuj A. (2015), Selected aspects of development management in the areas affected by urban sprawl process in Poland, Public Management, Scientific Journal of the Institute of Public Affairs of the Jagiellonian University, 1(29).

[11] Hołuj A. (2015), Challenges of local selfgovernment in terms of progressive depreciation of space as a result of the urban sprawl, proposing a methodology for optimal delimitation of areas, Culture and Politics (ed.) C. Calm, European Higher School for them. Fr. J. Tischnera.

[12] Hołuj A., Frączek J. (2015), The Importance of the Measurement and Analysis of Vehicle Traffic Volume for Designing Road Infrastructure: a Case Study of Bysina, Infrastructure and Ecology of Rural Areas, 4(4).

[13] Hołuj A., Zawilińska B. (2013), Planning Documents Issued in Poland at the Municipal Level. Example of the Krakow Metropolitan Area, Journal of Settlements and Spatial Planning, 4(1).

[14] *** (2016), Information for the Meeting of the Local Government and Regional Policy Committee on 11 May 2016. Ministry of Infrastructure and Construction of the Republic of Poland, Warsaw.

[15] *** (2011), National Spatial Development Concept 2030 Ministry of Regional Development of the Republic of Poland, Warsaw.

[16] Kowalewski, A., Mordasiewicz, J., Osiatyński, J., Regulski, J., Stępień, J., Śleszyński, P. (2014), Report on Economic Losses and Social Costs of Uncontrolled Urbanization in Poland, Foundation for the Development of Local Democracy, Self-Government 4/2014, Warsaw.

[17] Lityński P. (2014), The Economic Consequences of Urban Decentralisation and Centralisation in the Light of Foreign Literature, Cracow Review of Economics and Management, 12(936), Cracow. 
[18] Lityński, P. (2015), Degree and Features of Urban Sprawl in Selected the Biggest Polish Cities, Research Papers of Wroclaw University of Economics, 402, Economic Policy.

[19] Lityński, P. (2016), The correlation between urban sprawl and the local economy in Poland, Urban Challenge, 27(2)/2016, Slovenia.

[20] Lityński, P., Hołuj, A. (2015), The Profile of Households Generating Urban Sprawl on the Example of a Selected Area of Cracow Metropolitan Area, [in:] T. Kudłacz, P. Lityński (ed.), The Management of Space in Cities and Regions - Conditions and Directions, Study of the Committee for Spatial Economy and Regional Planning, Polish Academy of Sciences, t. CLXI. [21] Metz, D. (2008), The myth of travel time saving, Transport Reviews, 28(3).

[22] Mills, E. S. (1999), The Brawl Over So-Called Sprawl, Illinois Real Estate Letter.

[23] O'Farrell, P. N., Markham, J. (1975), Commuting costs and residential location, Tijdschriftvoor Economischeen Sociale Geografie, 66(2).

[24] Perrsky, J., Wiewel, J. (2012), Urban Decentralization, Suburbanization, and Sprawl: An Equity Perspective, [in:] N. Brooks, K. Donaghy, G.J. Knaap (ed.), Urban Economics and Planning, Oxford University Press, New York.

[25] *** (2007), Regulation of the Minister of Transport of 23 October 2007 amending the ordinance on the conditions of establishing and the manner of reimbursement for the use of official cars, motorcycles and mopeds not owned by the employer. OJ 2007 No. 201 pos. 1462.
[26] Schafer, A., Victor, D. G. (2000), The future mobility of the world population, Transportation Research Part A, 34(3).

[27] Sepiol, J. (ed.). (2015), Space of Polish Life, Warsaw.

[28] Śleszyński, P. (2012), Commuting Directions, Statistical News, Central Statistical Office of Poland and Polish Statistical Association, Poland.

[29] Śleszyński, P. (2013), Delimitation of the Functional Urban Areas around Poland's voivodship capital cities, Geographical Review, Institute of Geography and Spatial Organization Polish Academy of Sciences, 85(2).

[30] Śleszyński, P. (2013), Warsaw as a Commuting Centre, Regional and Local Studies, 51(1).

[31] Van Ommeren, J., Rietveld, P., Nijkamp, P. (1999), Job moving, residential moving, and commuting: a search perspective, Journal of Urban Economics, 46(2).

[32] Wassmer, R. W. (2002), An Economic Perspective on Urban Sprawl: With an Application to the American West and a Test of the Efficiency of Urban Growth Boundaries, California State University. [33] Weisbrod, G., Ben-Akiva, M., Lerman, S. (1980), Tradeoffs in residential location decisions: transportation versus other factors, Transportation Policy and Decision-Making, 1(1).

[34] *** (2016), Guidance on Macroeconomic Assumptions for Multi-Annual Financial Projections of Local Government Units. Update - May 2016, Ministry of Finance of the Republic of Poland, Warsaw. 
APPENDIX 1. Losses of households located in municipalities of Functional Urban Areas in Poland. Diagnosis and Forecast

\section{BIAEYSTOK}

Fig. 1. The direct annual financial losses due to commuting to and from the city core per household $[€, \mathrm{k}]$.

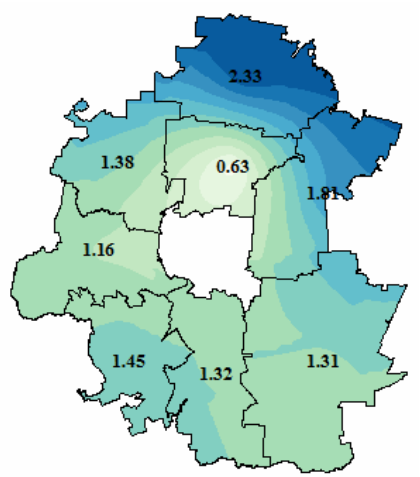

Fig. 3. The annual value of lost time due to commuting to and from the city core per household $[€, \mathrm{k}]$.

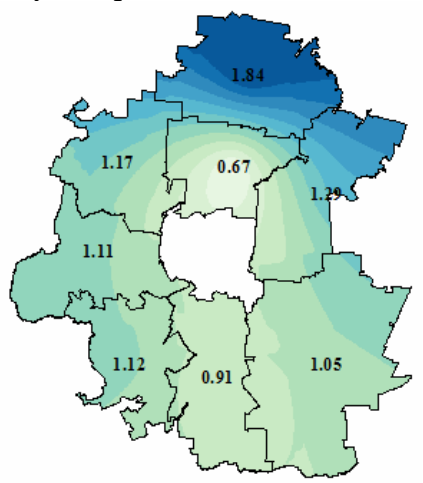

Fig. 5. The direct annual financial losses and the value of lost time due to commuting to and from the city core per household [€, $\mathrm{k}]$.

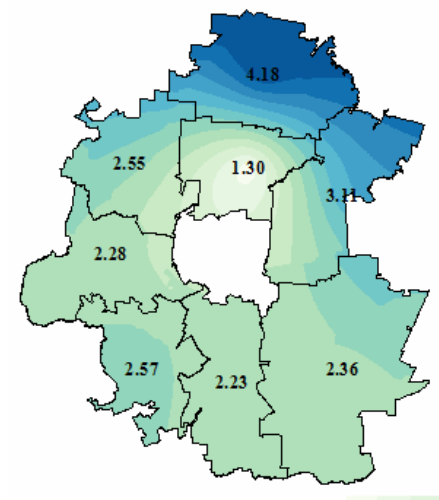

$\min$
Fig. 2. The projection of the direct financial losses due to commuting to and from the city core per household, 2017-2030 [€, $\mathrm{k}]$.

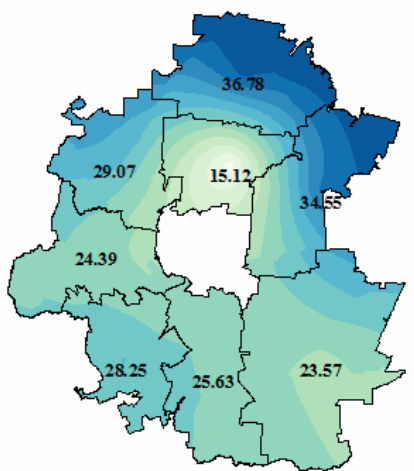

Fig. 4. The projection of the value of lost time due to commuting to and from the city core per household, 2017-2030 [€, k].

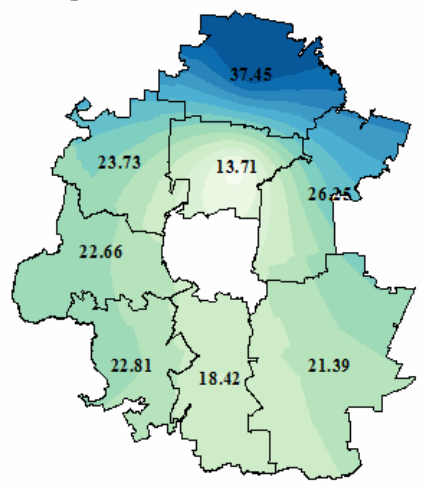

Fig. 6. The projection of direct financial losses and the value of lost time due to commuting to and from the city core per one household, 2017-2030 [€, k].

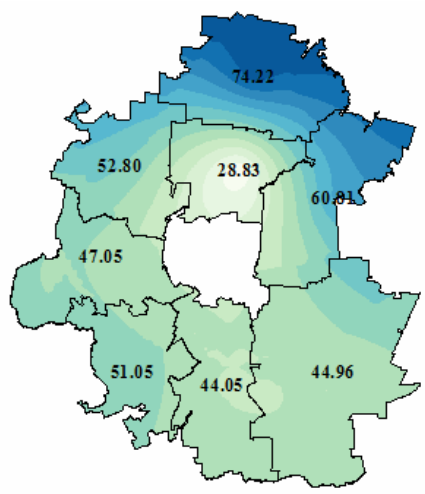




\section{BYDGOSZCZ AND TORUŃ}

Fig. 1. The direct annual financial losses due to commuting to and from the city core per household $[€, \mathrm{k}]$

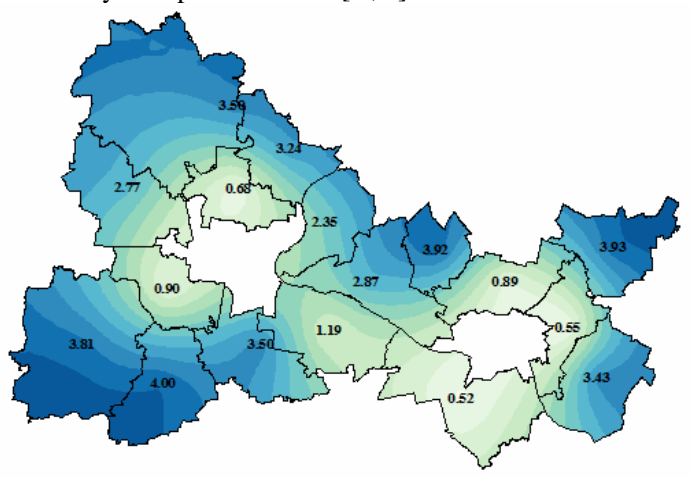

Fig. 3. The annual value of lost time due to commuting to and from the city core per household $[€, \mathrm{k}]$

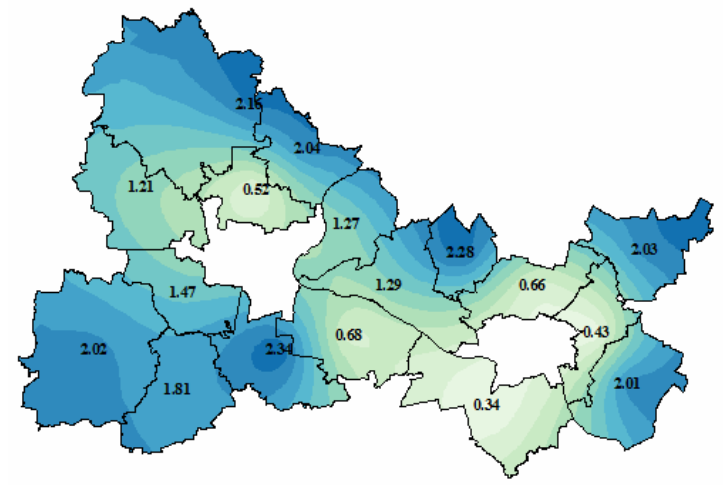

Fig. 5. The direct annual financial losses and the value of lost time due to commuting to and from the city core per household $[€, \mathrm{k}]$

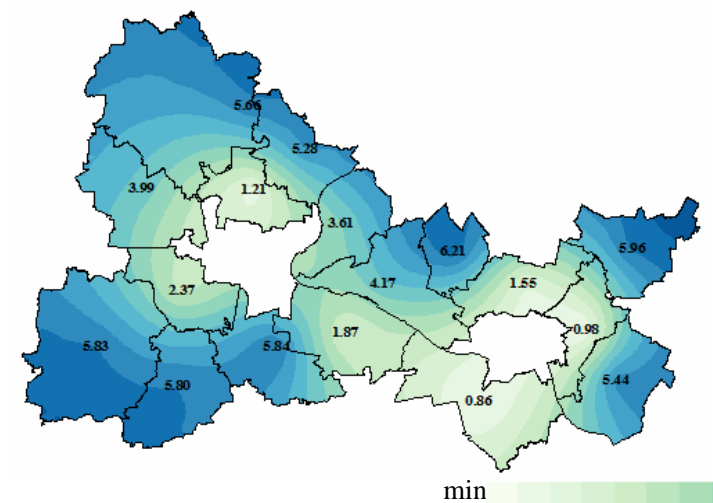

Fig. 2. The projection of the direct financial losses due to commuting to and from the city core per household, 2017-2030 [€, k]

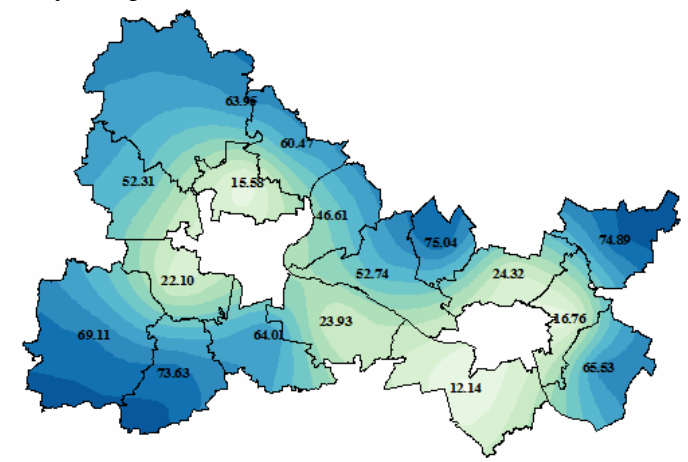

Fig. 4. The projection of the value of lost time due to commuting to and from the city core per household, 2017-2030 [€, k]

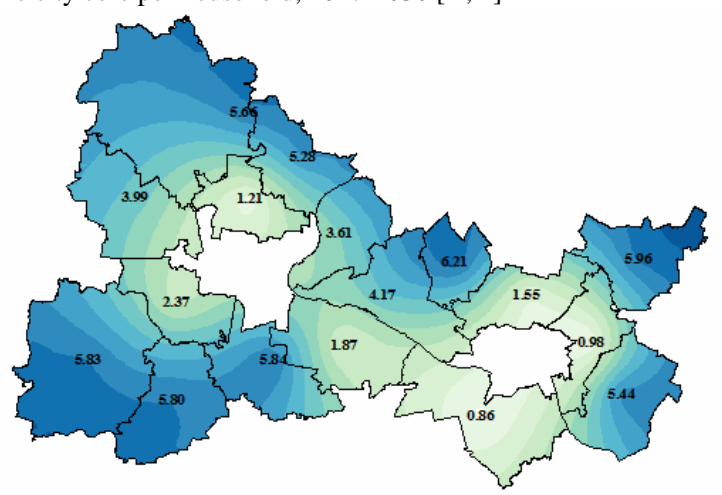

Fig. 6. The projection of direct financial losses and the value of lost time due to commuting to and from the city core per one household, 2017-2030 $[€, \mathrm{k}]$

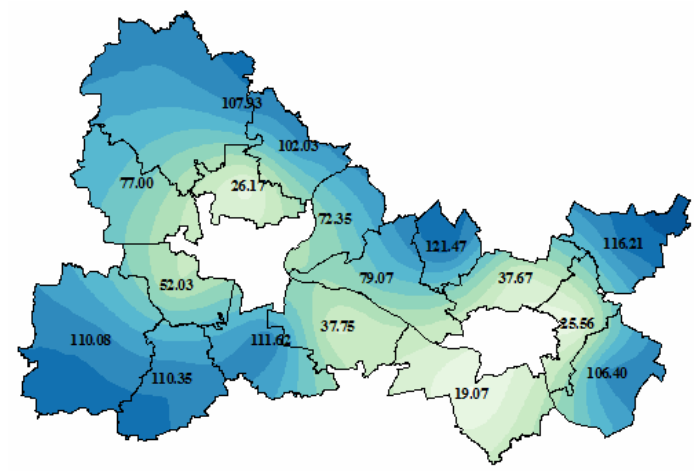


Urban Sprawl Costs: The Valuation of Households' Losses in Poland

Journal Settlements and Spatial Planning, vol. 8, no. 1 (2017) 11-35

\section{GDAŃSK-GDYNIA-SOPOT}

Fig. 1. The direct annual financial losses due to commuting to and from the city core per household $[€, \mathrm{k}]$

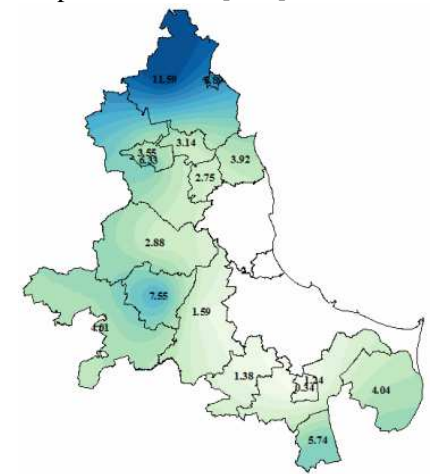

Fig. 3. The annual value of lost time due to commuting to and from the city core per household $[€, \mathrm{k}]$

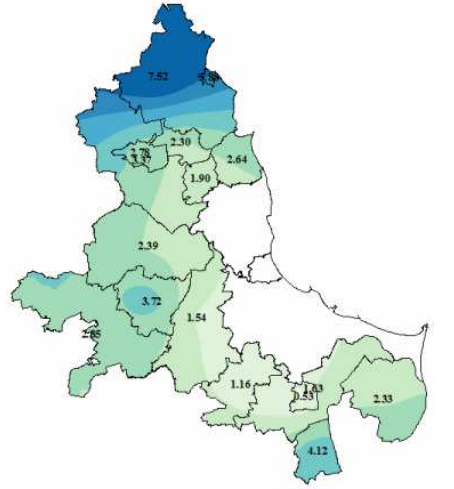

Fig. 5. The direct annual financial losses and the value of lost time due to commuting to and from the city core per household [ $€, \mathrm{k}]$

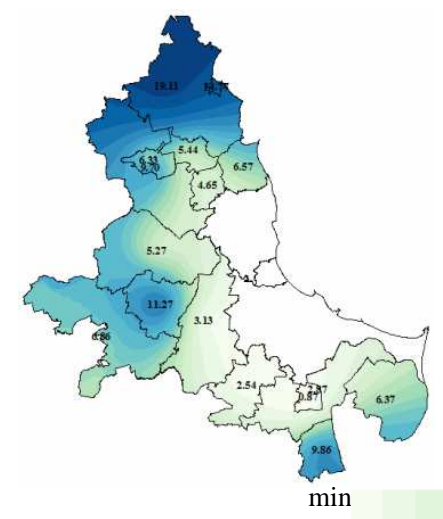

Fig. 2. The projection of the direct financial losses due to commuting to and from the city core per household, 2017-2030 [€, k]

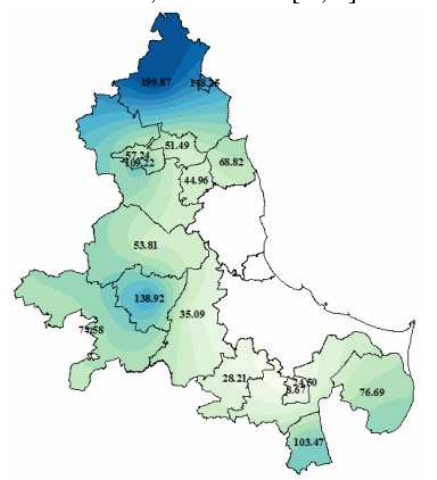

Fig. 4. The projection of the value of lost time due to commuting to and from the city core per household, 2017-2030 [€, k]

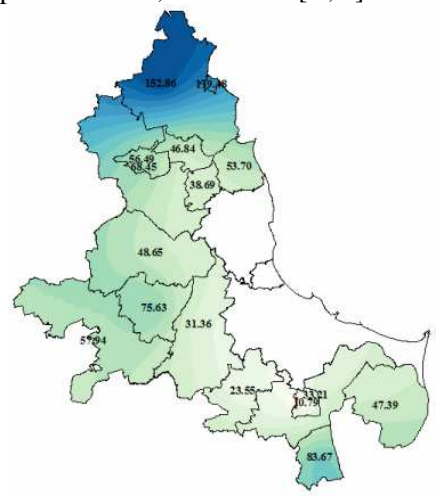

Fig. 6. The projection of direct financial losses and the value of lost time due to commuting to and from the city core per one household, 2017-2030 $[€, \mathrm{k}]$

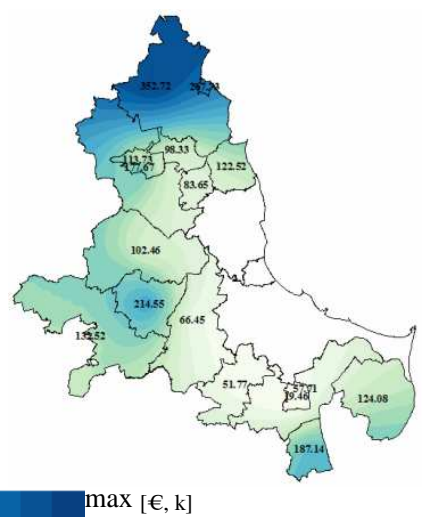




\section{GORZÓW WIELKOPOLSKI}

Fig. 1. The direct annual financial losses due to commuting to and from the city core per household $[€, \mathrm{k}]$

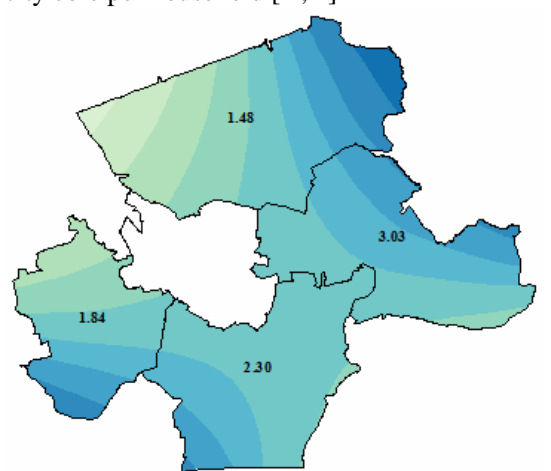

Fig. 3. The annual value of lost time due to commuting to and from the city core per household $[€, \mathrm{k}]$

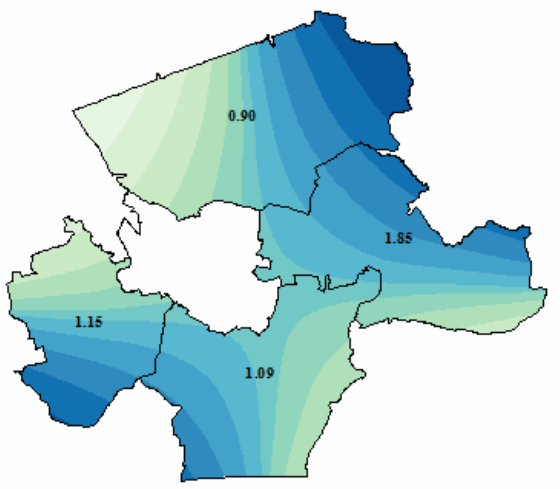

Fig. 5. The direct annual financial losses and the value of lost time due to commuting to and from the city core per household [ $€, \mathrm{k}]$

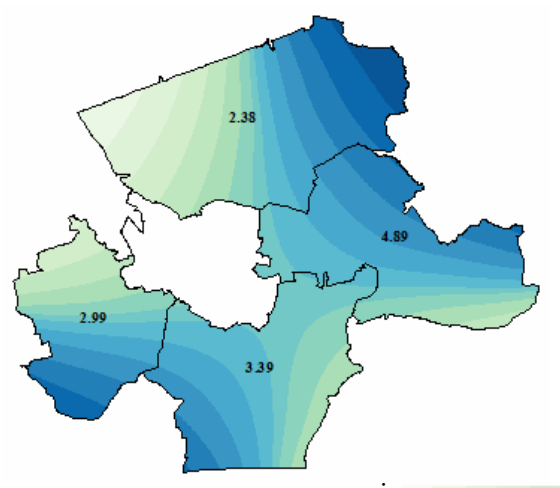

$\min$
Fig. 2. The projection of the direct financial losses due to commuting to and from the city core per household, 2017-2030 [€, k]

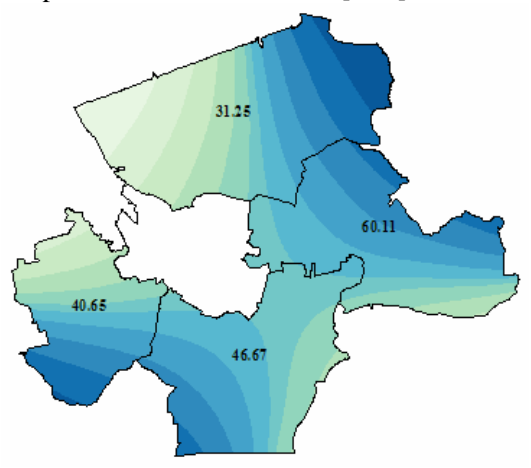

Fig. 4. The projection of the value of lost time due to commuting to and from the city core per household, 2017-2030 [€, k]

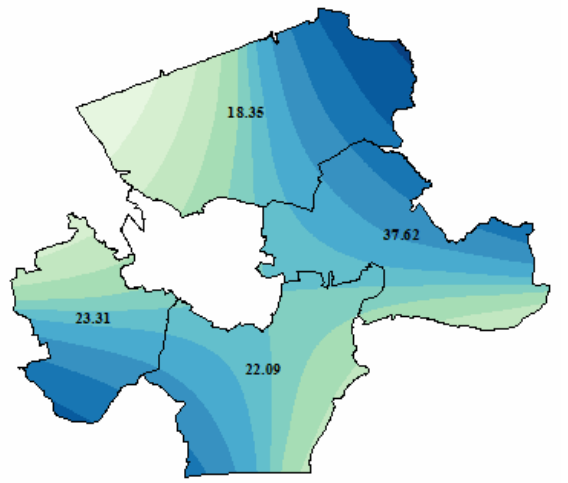

Fig. 6. The projection of direct financial losses and the value of lost time due to commuting to and from the city core per one household, 2017-2030 $[€, \mathrm{k}]$

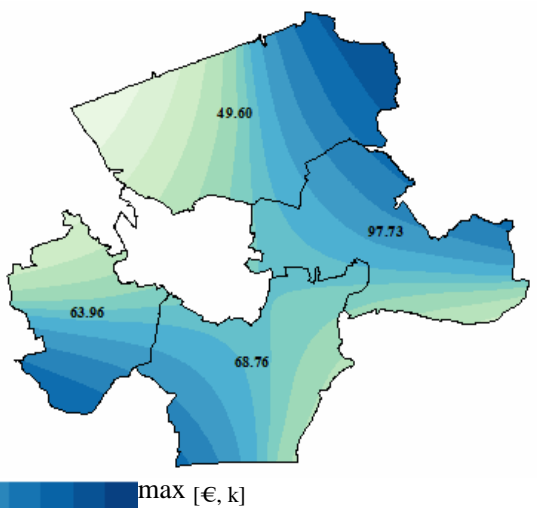




\section{KATOWICE}

Fig. 1. The direct annual financial losses due to commuting to and from the city core per household [€, k]

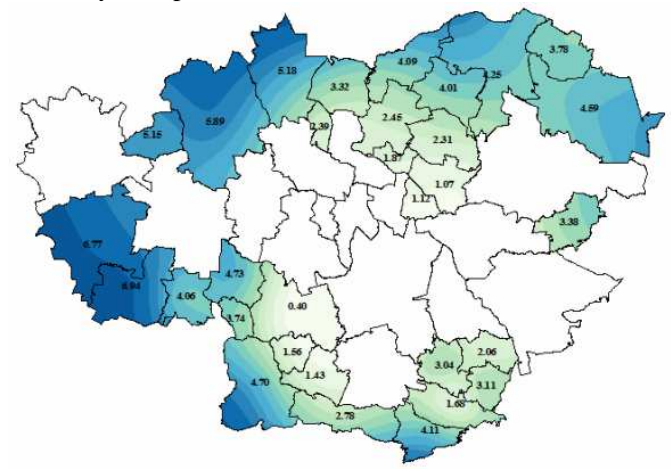

Fig. 3. The annual value of lost time due to commuting to and from the city core per household $[€, \mathrm{k}]$

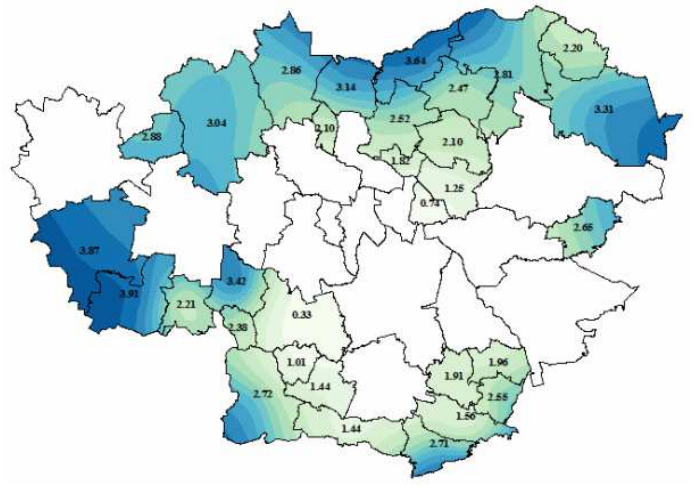

Fig. 5. The direct annual financial losses and the value of lost time due to commuting to and from the city core per household $[€, \mathrm{k}]$

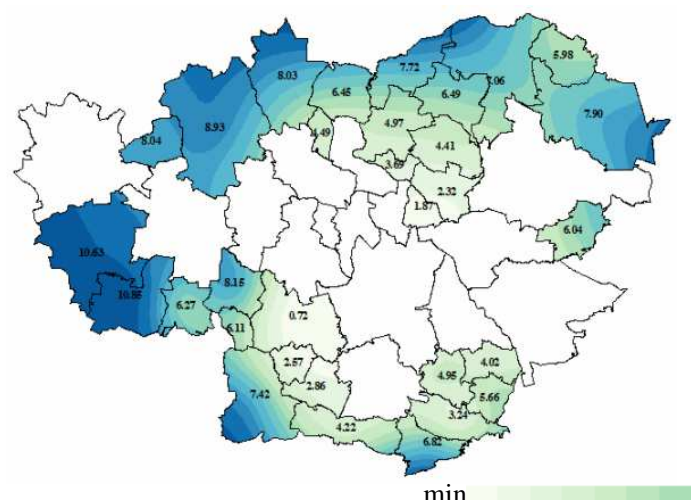

Fig. 2. The projection of the direct financial losses due to commuting to and from the city core per household, 2017-2030 [€, k]

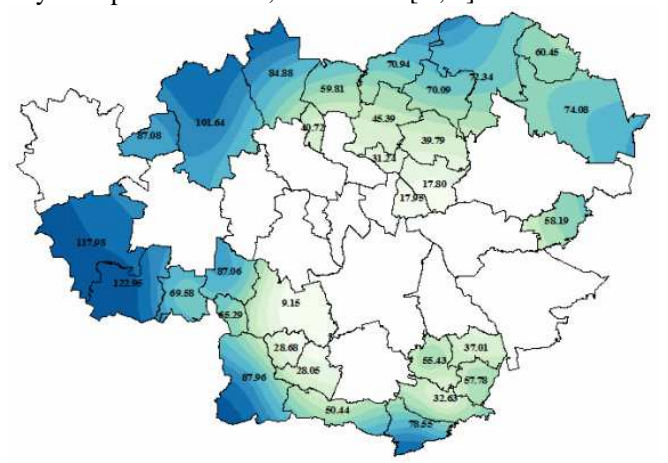

Fig. 4. The projection of the value of lost time due to commuting to and from the city core per household, 2017-2030 [€, k]

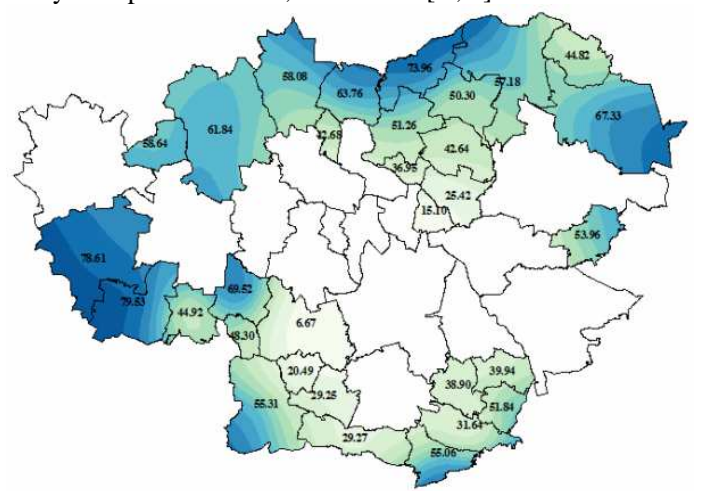

Fig. 6. The projection of direct financial losses and the value of lost time due to commuting to and from the city core per one household, 2017-2030 [€, k]

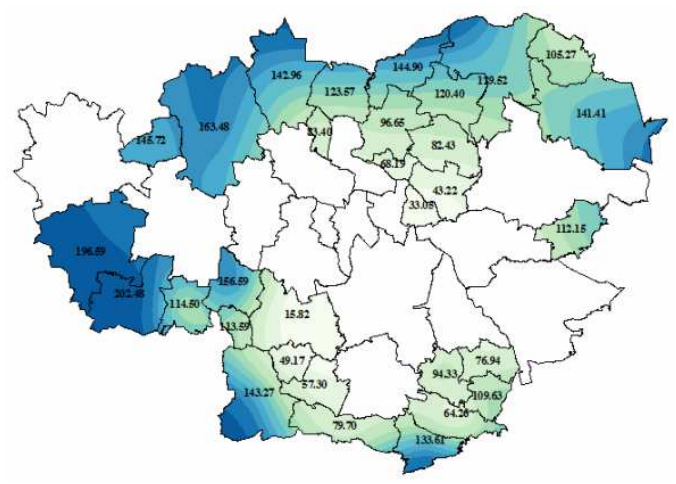




\section{KIELCE}

Fig. 1. The direct annual financial losses due to commuting to and from the city core per household $[€, \mathrm{k}]$

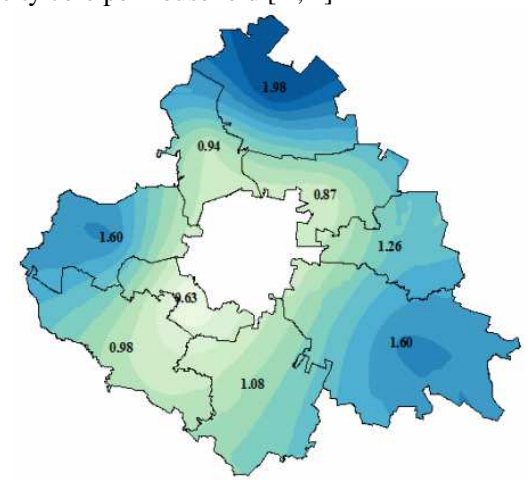

Fig. 3. The annual value of lost time due to commuting to and from the city core per household $[€, \mathrm{k}]$

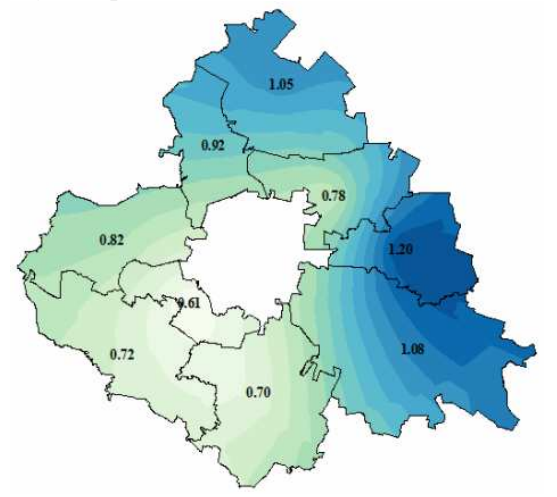

Fig. 5. The direct annual financial losses and the value of lost time due to commuting to and from the city core per household [ $€, \mathrm{k}]$

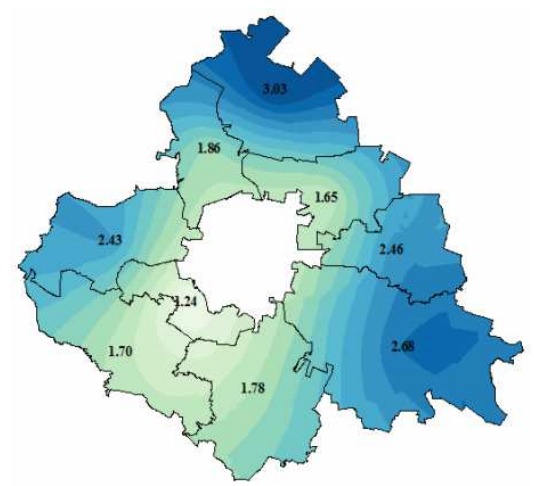

$\min$
Fig. 2. The projection of the direct financial losses due to commuting to and from the city core per household, 2017-2030 [€, k]

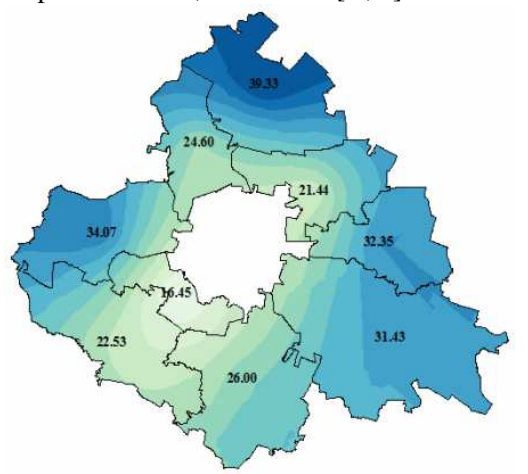

Fig. 4. The projection of the value of lost time due to commuting to and from the city core per household, 2017-2030 [€, k]

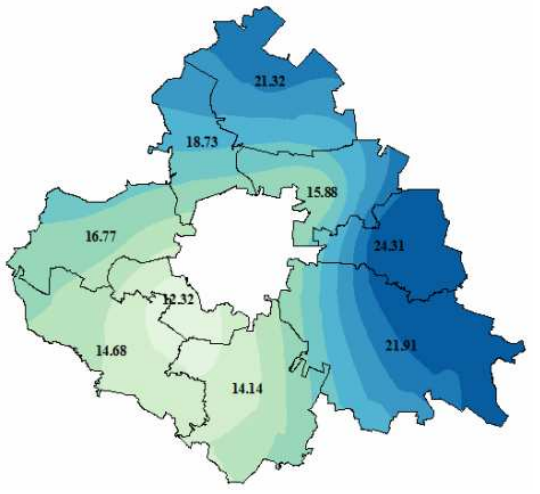

Fig. 6. The projection of direct financial losses and the value of lost time due to commuting to and from the city core per one household, 2017-2030 $[€, \mathrm{k}]$

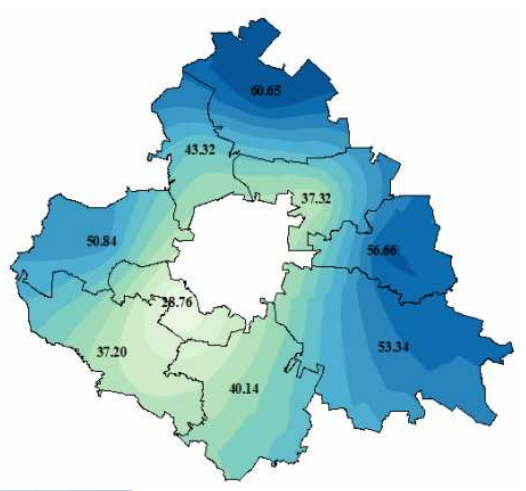

$\max [€, \mathrm{k}]$ 


\section{KRAKÓW}

Fig. 1. The direct annual financial losses due to commuting to and from the city core per household $[€, \mathrm{k}]$

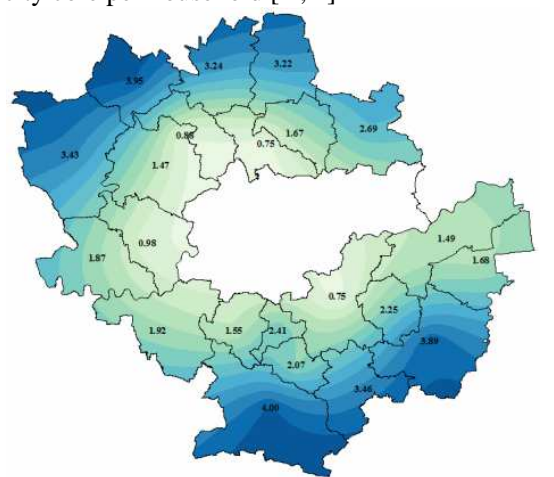

Fig. 3. The annual value of lost time due to commuting to and from the city core per household $[€, \mathrm{k}]$

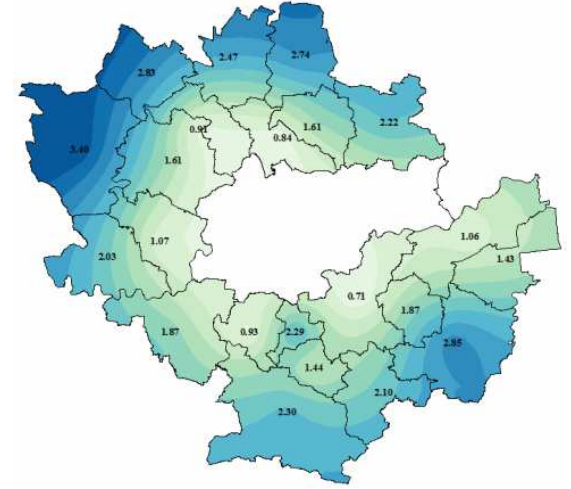

Fig. 5. The direct annual financial losses and the value of lost time due to commuting to and from the city core per household $[€, \mathrm{k}]$

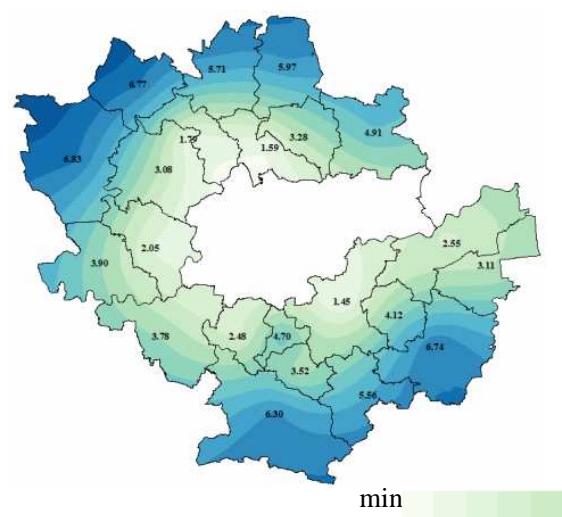

Fig. 2. The projection of the direct financial losses due to commuting to and from the city core per household, 2017-2030 [€, k]

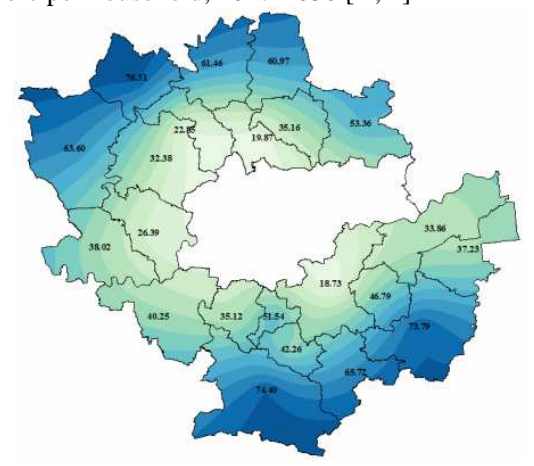

Fig. 4. The projection of the value of lost time due to commuting to and from the city core per household, 2017-2030 [€, k]

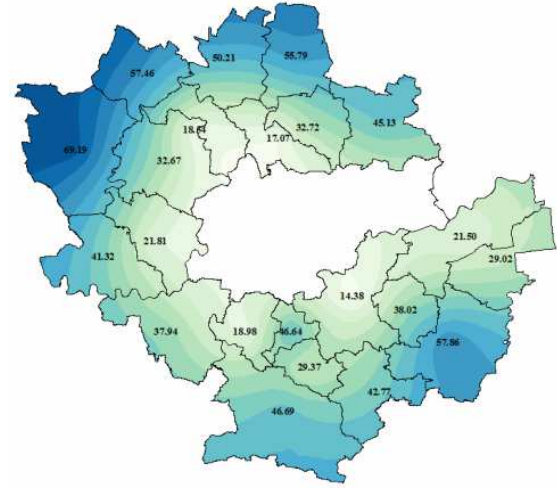

Fig. 6. The projection of direct financial losses and the value of lost time due to commuting to and from the city core per one household, 2017-2030 [€, k]

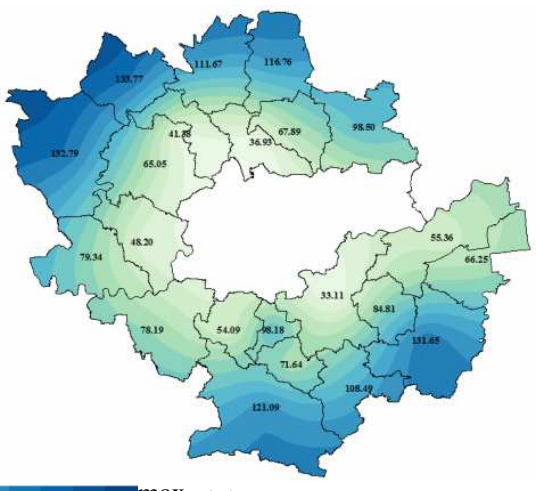




\section{LUBLIN}

Fig. 1. The direct annual financial losses due to commuting to and from the city core per household $[€, \mathrm{k}]$

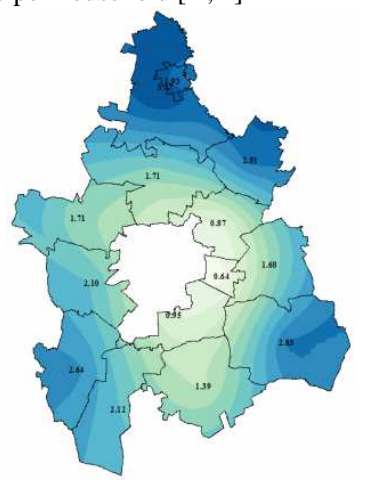

Fig. 3. The annual value of lost time due to commuting to and from the city core per household $[€, \mathrm{k}]$

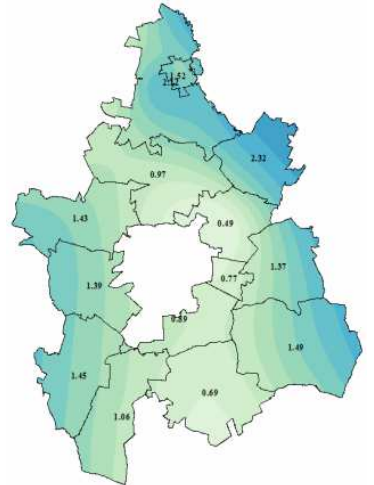

Fig. 5. The direct annual financial losses and the value of lost time due to commuting to and from the city core per household $[€, \mathrm{k}]$

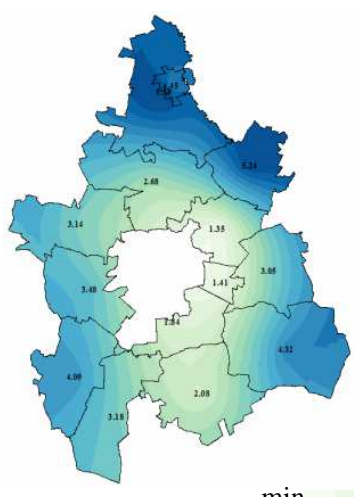

Fig. 2. The projection of the direct financial losses due to commuting to and from the city core per household, 2017-2030 [€, k]

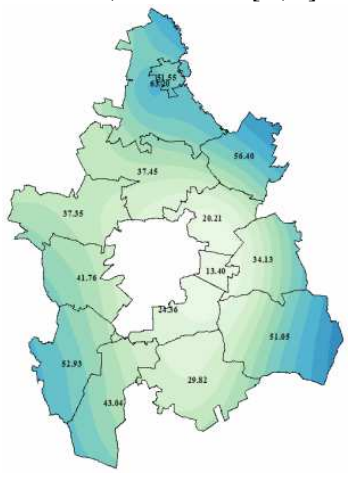

Fig. 4. The projection of the value of lost time due to commuting to and from the city core per household, 2017-2030 [€, k]

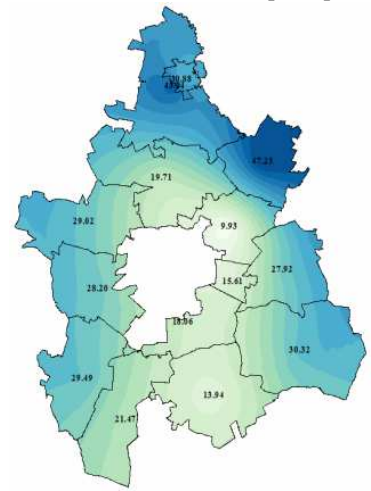

Fig. 6. The projection of direct financial losses and the value of lost time due to commuting to and from the city core per one household, 2017-2030 $[€, \mathrm{k}]$

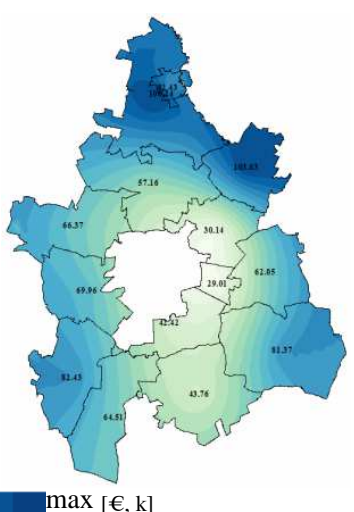




\section{ŁÓDŹ}

Fig. 1. The direct annual financial losses due to commuting to and from the city core per household $[€, \mathrm{k}]$

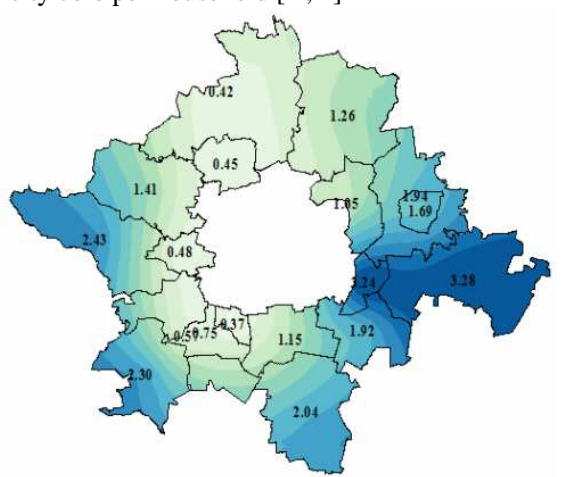

Fig. 3. The annual value of lost time due to commuting to and from the city core per household $[€, \mathrm{k}]$

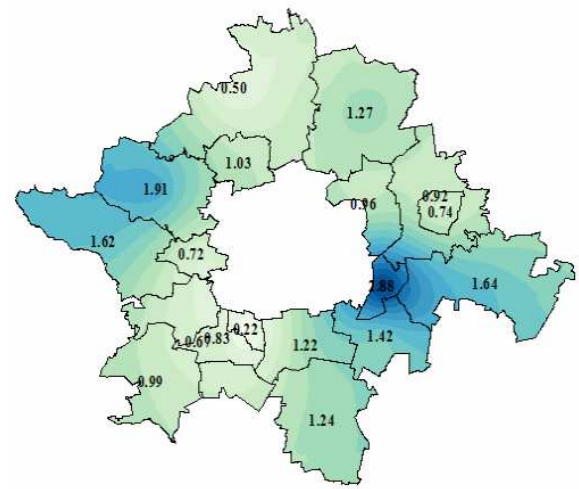

Fig. 5. The direct annual financial losses and the value of lost time due to commuting to and from the city core per household $[€, \mathrm{k}]$

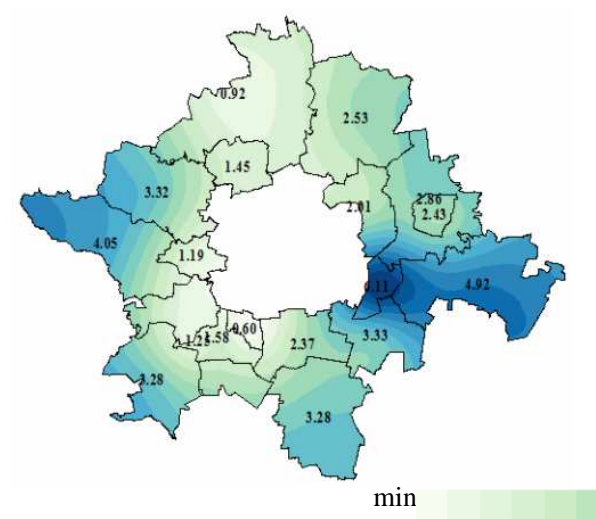

Fig. 2. The projection of the direct financial losses due to commuting to and from the city core per household, 2017-2030 [€, k]

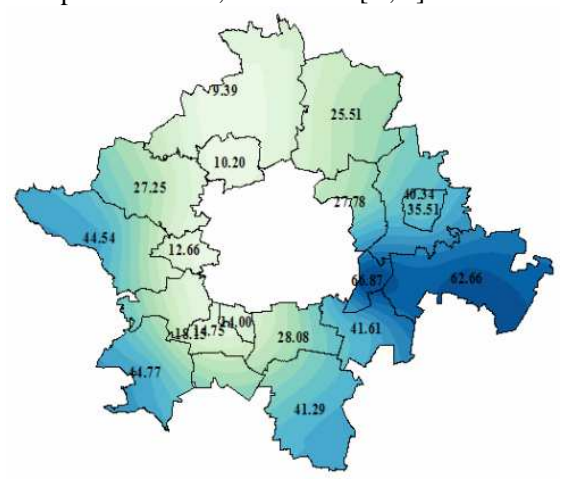

Fig. 4. The projection of the value of lost time due to commuting to and from the city core per household, 2017-2030 [€, k]

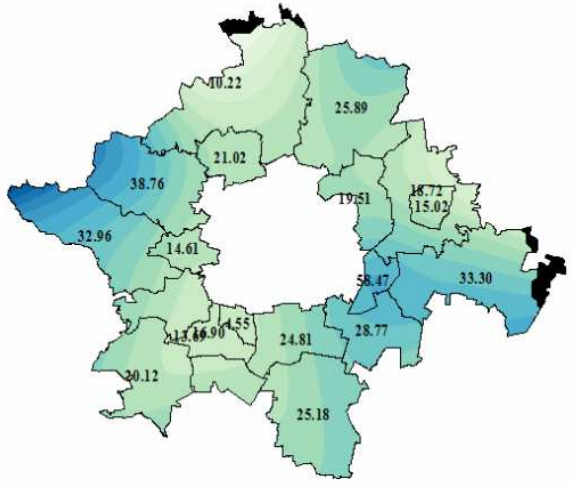

Fig. 6. The projection of direct financial losses and the value of lost time due to commuting to and from the city core per one household, 2017-2030 $[€, \mathrm{k}]$

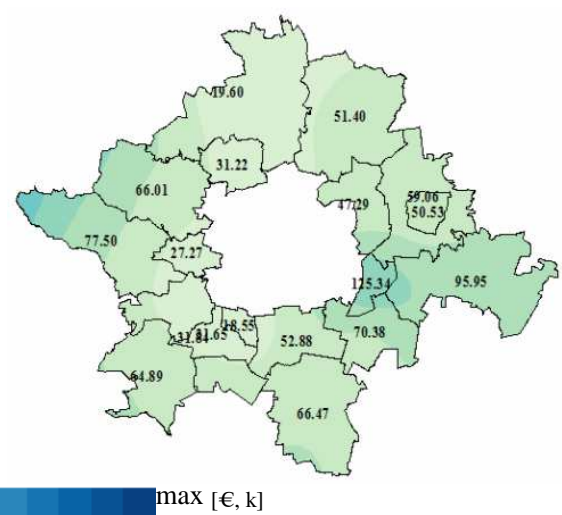




\section{OLSZTYN}

Fig. 1. The direct annual financial losses due to commuting to and from the city core per household $[€, \mathrm{k}]$

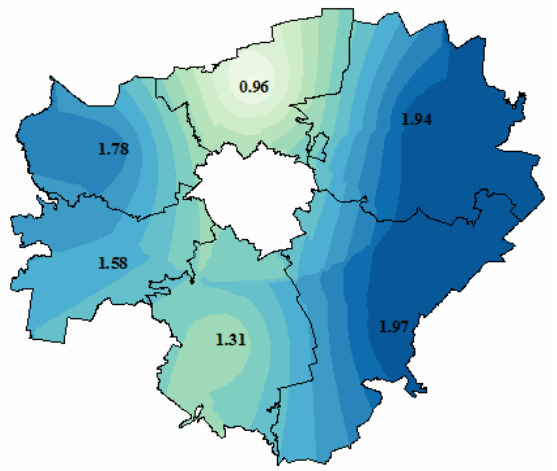

Fig. 3. The annual value of lost time due to commuting to and from the city core per household $[€, \mathrm{k}]$

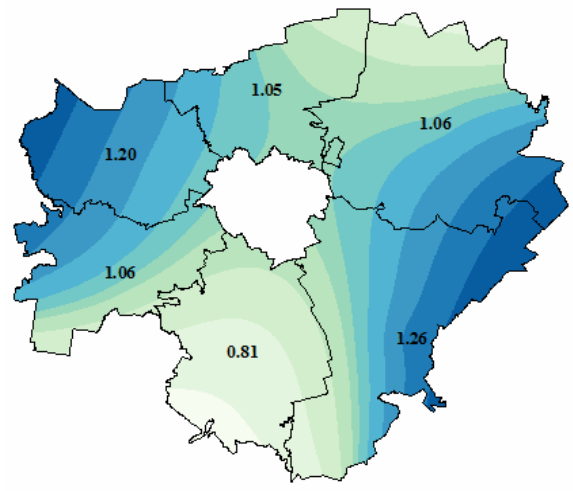

Fig. 5. The direct annual financial losses and the value of lost time due to commuting to and from the city core per household $[€, \mathrm{k}]$

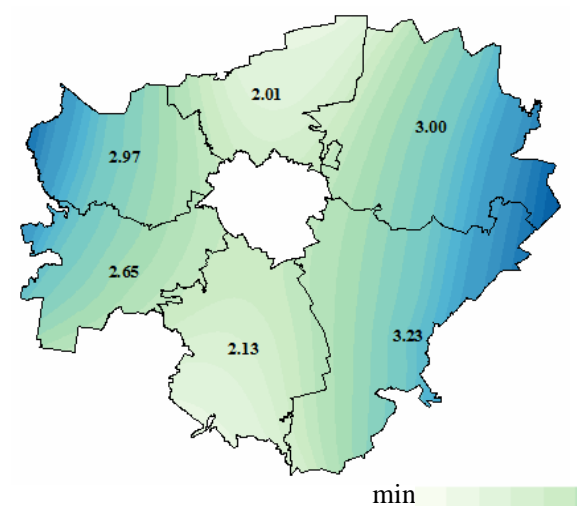

$\min$
Fig. 2. The projection of the direct financial losses due to commuting to and from the city core per household, 2017-2030 [€, k]

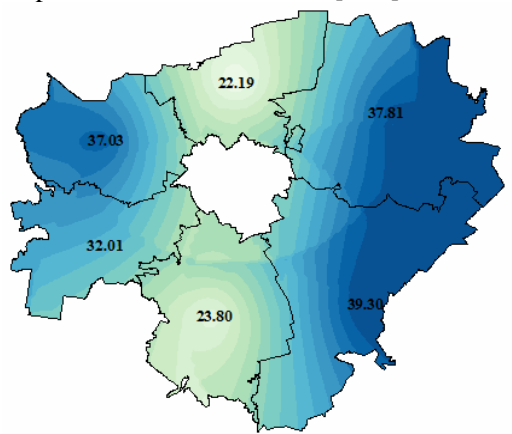

Fig. 4. The projection of the value of lost time due to commuting to and from the city core per household, 2017-2030 [€, k]

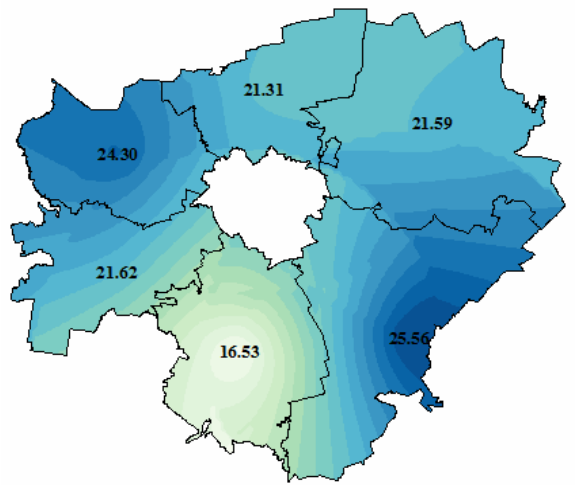

Fig. 6. The projection of direct financial losses and the value of lost time due to commuting to and from the city core per one household, 2017-2030 $[€, \mathrm{k}]$

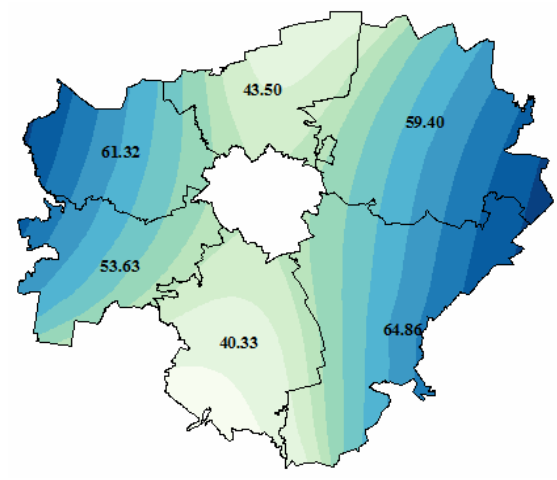




\section{OPOLE}

Fig. 1. The direct annual financial losses due to commuting to and from the city core per household $[€, \mathrm{k}]$

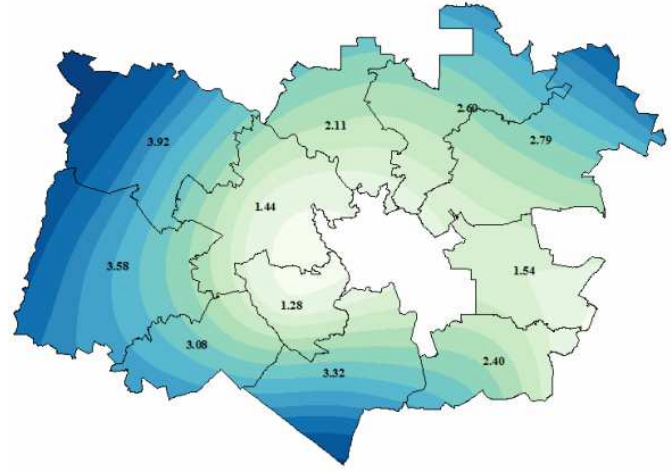

Fig. 3. The annual value of lost time due to commuting to and from the city core per household $[€, \mathrm{k}]$

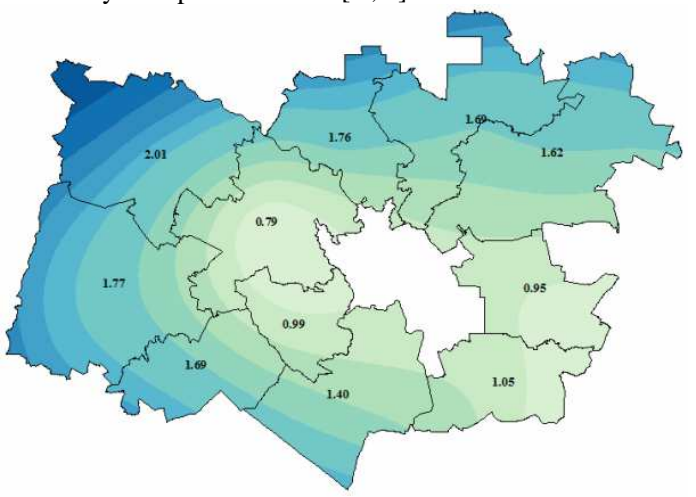

Fig. 5. The direct annual financial losses and the value of lost time due to commuting to and from the city core per household $[€, \mathrm{k}]$

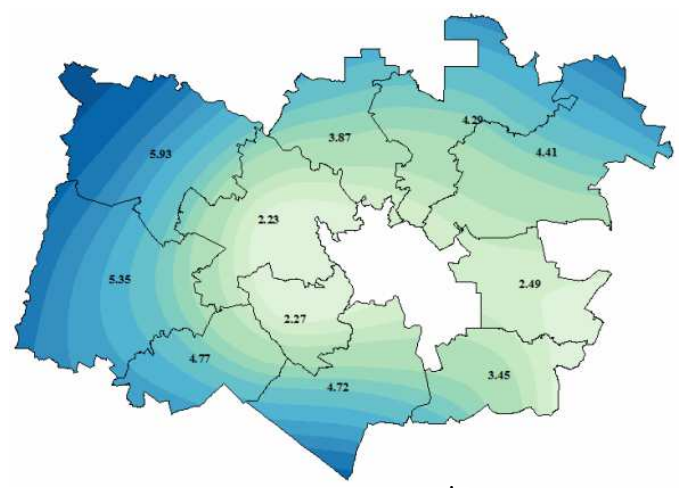

Fig. 2. The projection of the direct financial losses due to commuting to and from the city core per household, 2017-2030 [€, k]

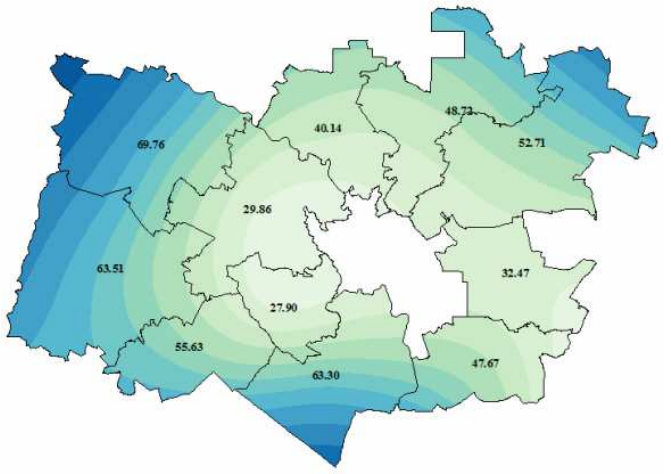

Fig. 4. The projection of the value of lost time due to commuting to and from the city core per household, 2017-2030 [€, k]

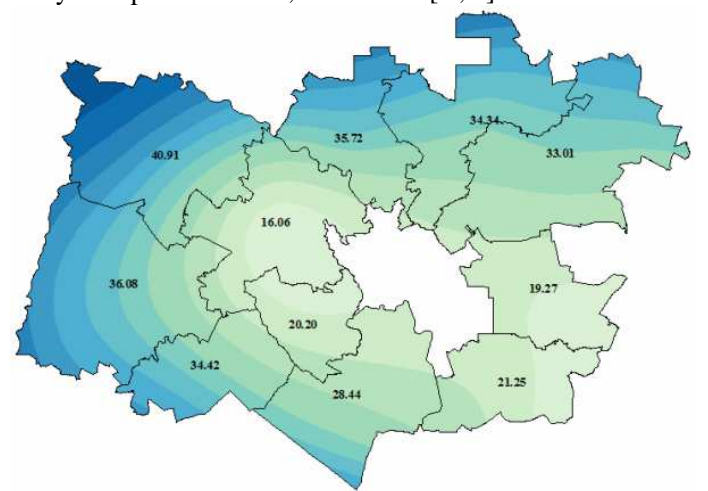

Fig. 6. The projection of direct financial losses and the value of lost time due to commuting to and from the city core per one household, 2017-2030 $[€, \mathrm{k}]$

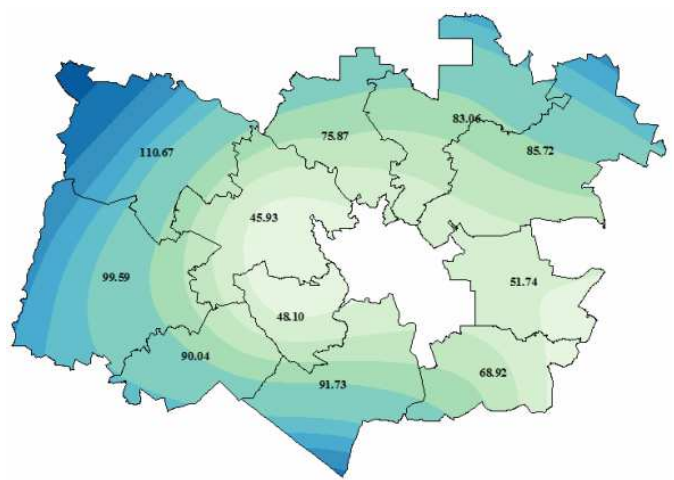

$\min$ 


\section{POZNAŃ}

Fig. 1. The direct annual financial losses due to commuting to and from the city core per household [€, k]

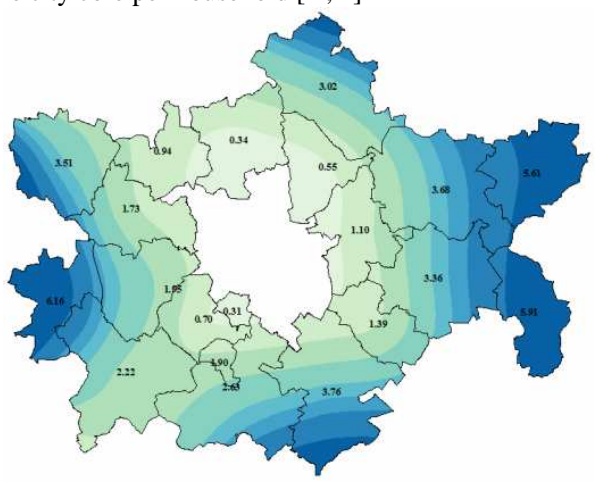

Fig. 3. The annual value of lost time due to commuting to and from the city core per household $[€, \mathrm{k}]$

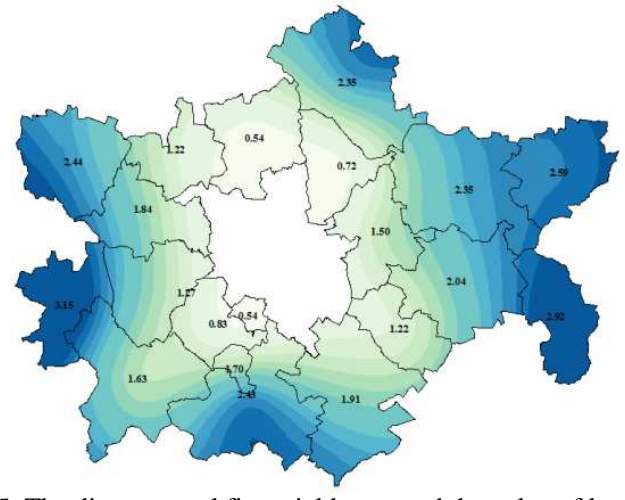

Fig. 5. The direct annual financial losses and the value of lost time due to commuting to and from the city core per household [ $€, \mathrm{k}]$

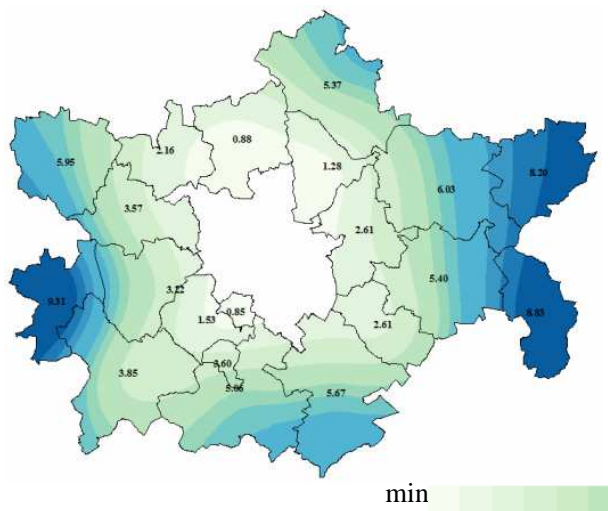

Fig. 2. The projection of the direct financial losses due to commuting to and from the city core per household, 2017-2030 [€, k]

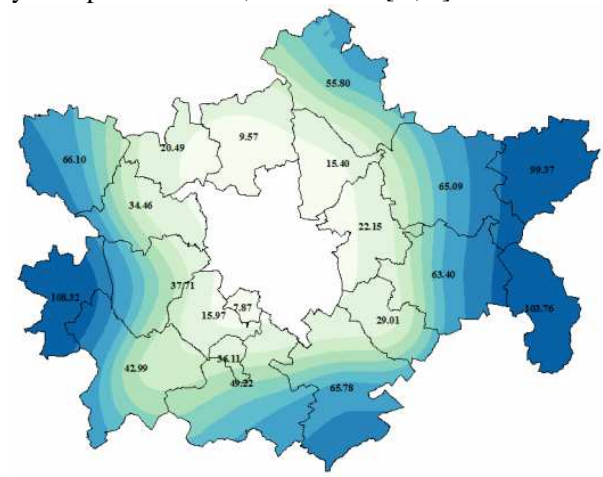

Fig. 4. The projection of the value of lost time due to commuting to and from the city core per household, 2017-2030 [€, k]

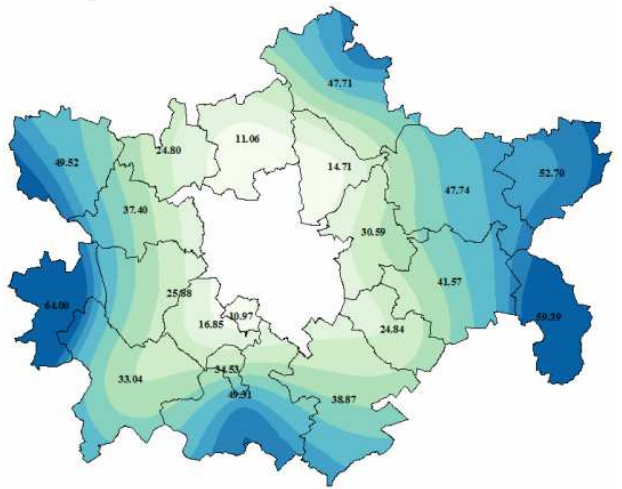

Fig. 6. The projection of direct financial losses and the value of lost time due to commuting to and from the city core per one household, 2017-2030 $[€, \mathrm{k}]$

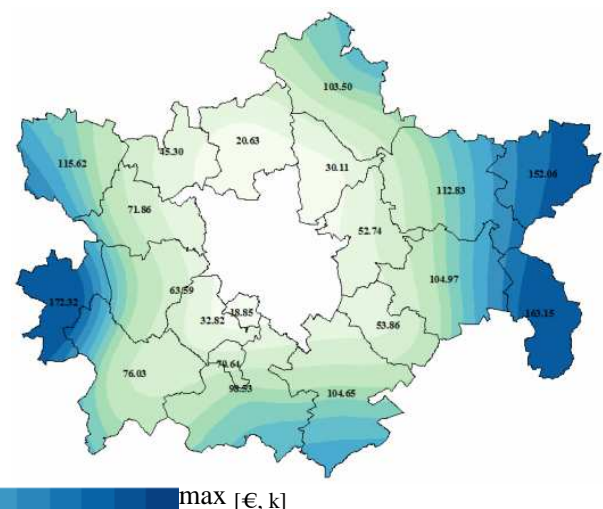




\section{RZESZóW}

Fig. 1. The direct annual financial losses due to commuting to and from the city core per household [€, k]

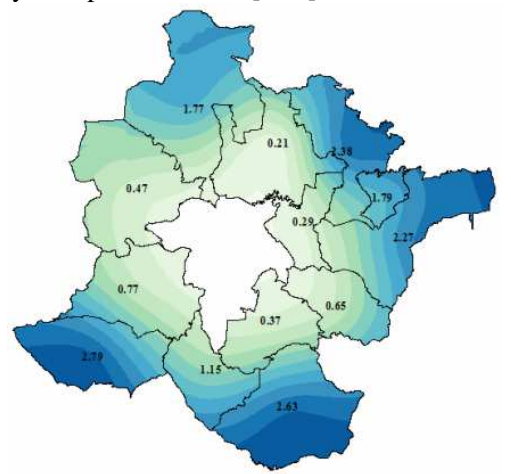

Fig. 3. The annual value of lost time due to commuting to and from the city core per household $[€, \mathrm{k}]$

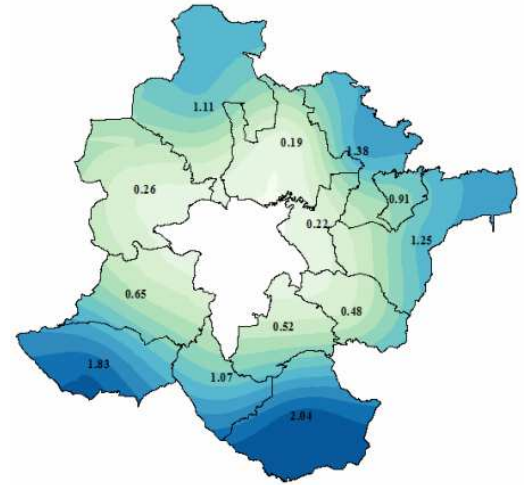

Fig. 5. The direct annual financial losses and the value of lost time due to commuting to and from the city core per household [€, $\mathrm{k}]$

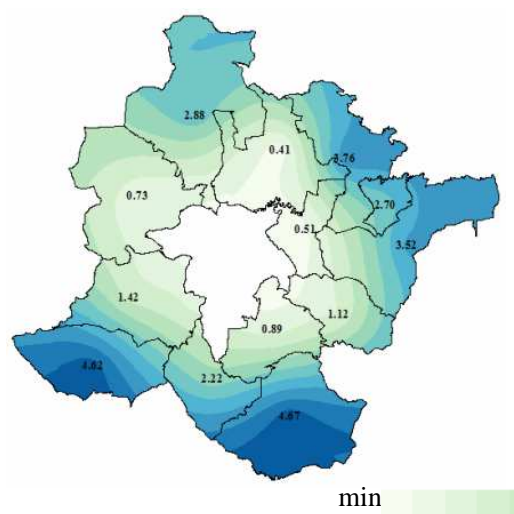

Fig. 2. The projection of the direct financial losses due to commuting to and from the city core per household, 2017-2030 [€, k]

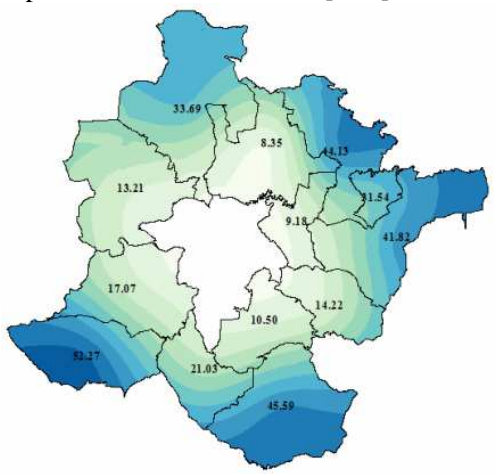

Fig. 4. The projection of the value of lost time due to commuting to and from the city core per household, 2017-2030 [€, k]

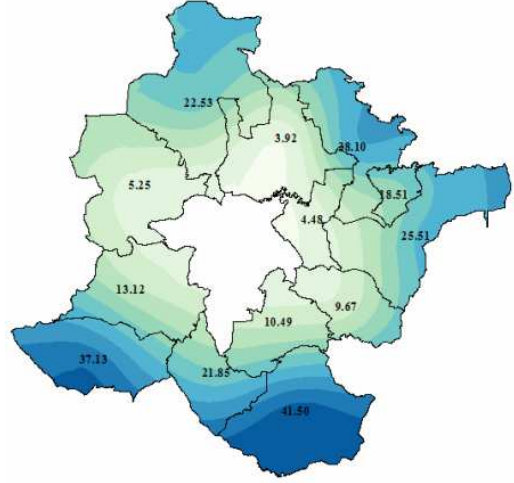

Fig. 6. The projection of direct financial losses and the value of lost time due to commuting to and from the city core per one household, 2017-2030 $[€, \mathrm{k}]$

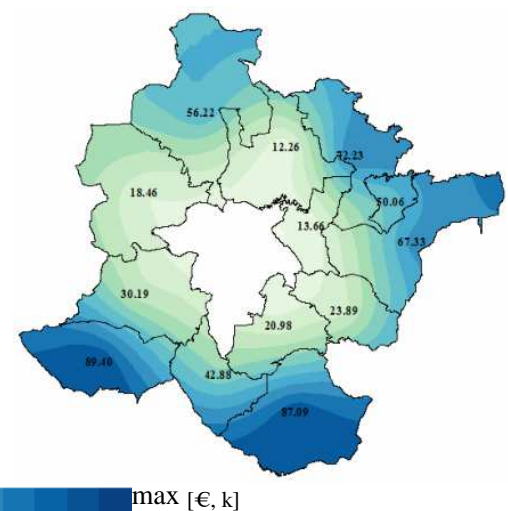




\section{SZCZECIN}

Fig. 1. The direct annual financial losses due to commuting to and from the city core per household $[€, \mathrm{k}]$

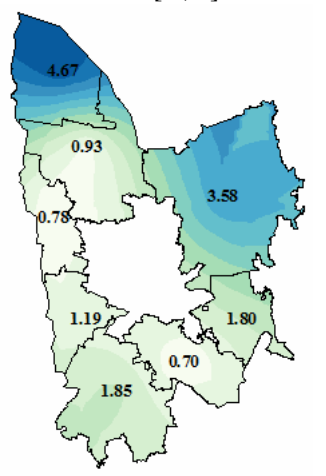

Fig. 3. The annual value of lost time due to commuting to and from the city core per household $[€, \mathrm{k}]$

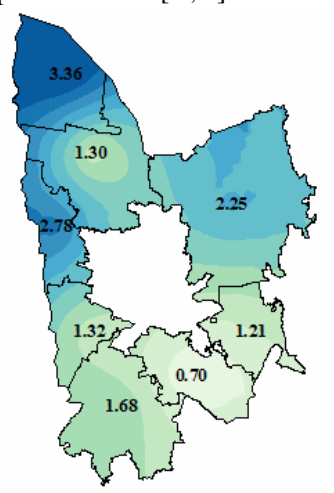

Fig. 5. The direct annual financial losses and the value of lost time due to commuting to and from the city core per household $[€, \mathrm{k}]$

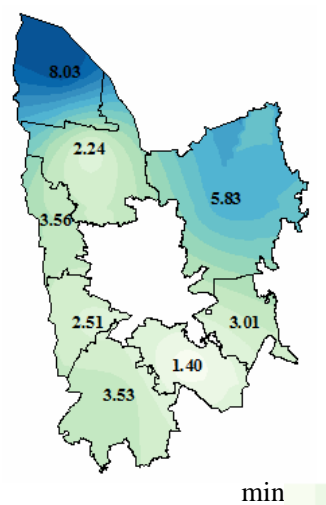

Fig. 2. The projection of the direct financial losses due to commuting to and from the city core per household, 2017-2030 [€, k]

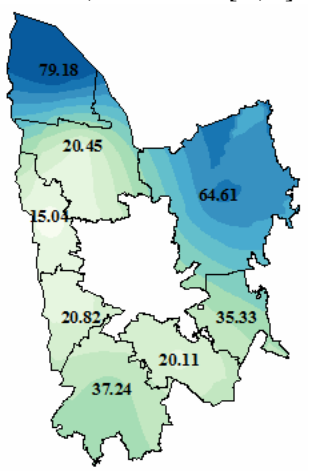

Fig. 4. The projection of the value of lost time due to commuting to and from the city core per household, 2017-2030 [€, k]

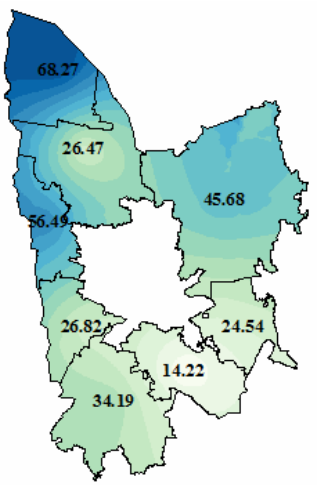

Fig. 6. The projection of direct financial losses and the value of lost time due to commuting to and from the city core per one household, 2017-2030 $[€, \mathrm{k}]$ 
Urban Sprawl Costs: The Valuation of Households' Losses in Poland

Journal Settlements and Spatial Planning, vol. 8, no. 1 (2017) 11-35

\section{WARSZAWA}

Fig. 1. The direct annual financial losses due to commuting to and from the city core per household $[€, \mathrm{k}]$

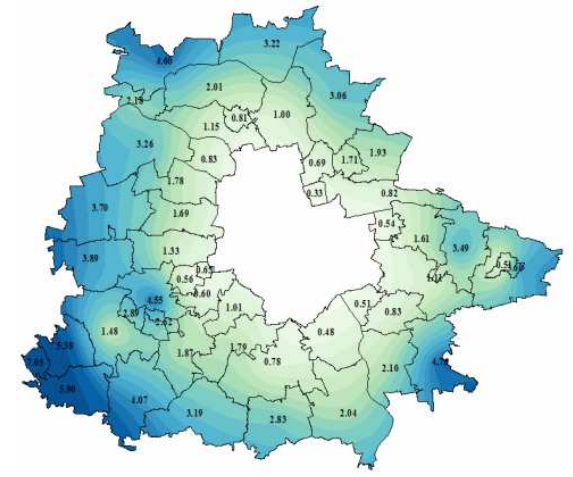

Fig. 3. The annual value of lost time due to commuting to and from the city core per household $[€, \mathrm{k}]$

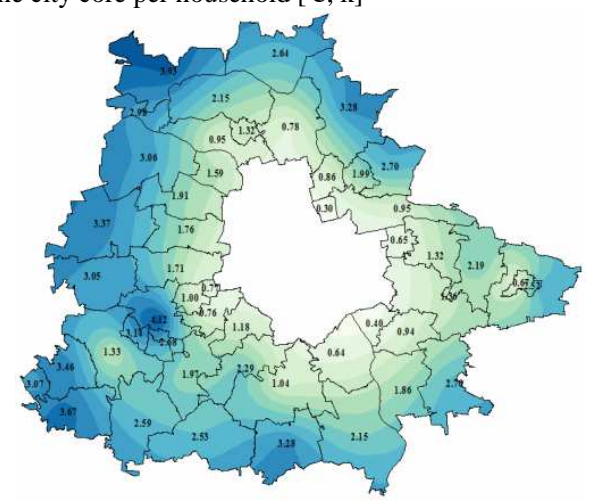

Fig. 5. The direct annual financial losses and the value of lost time due to commuting to and from the city core per household [ $€, \mathrm{k}]$

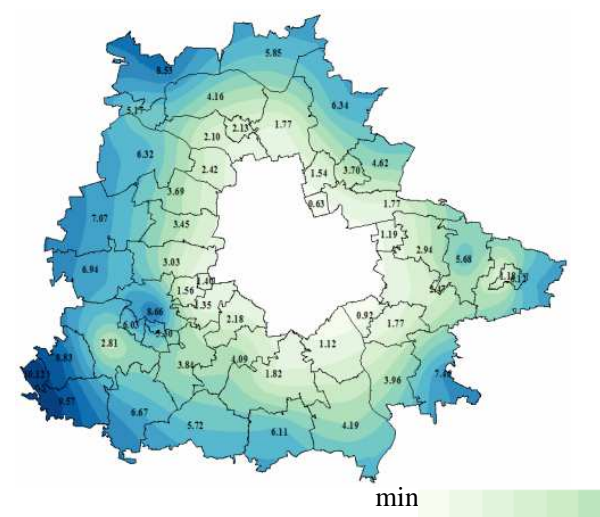

Fig. 2. The projection of the direct financial losses due to commuting to and from the city core per household, 2017-2030 [€, k]

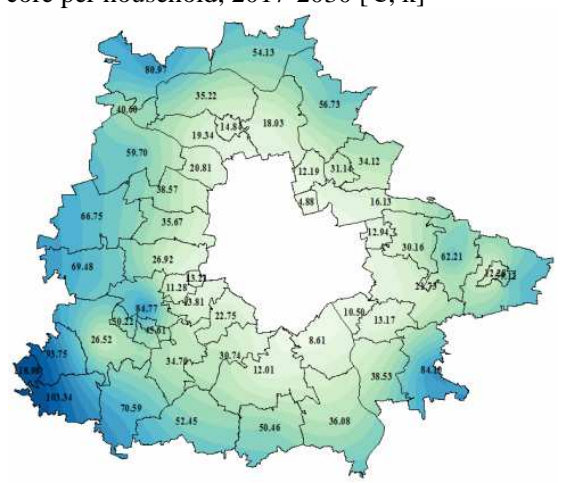

Fig. 4. The projection of the value of lost time due to commuting to and from the city core per household, 2017-2030 [€, k]

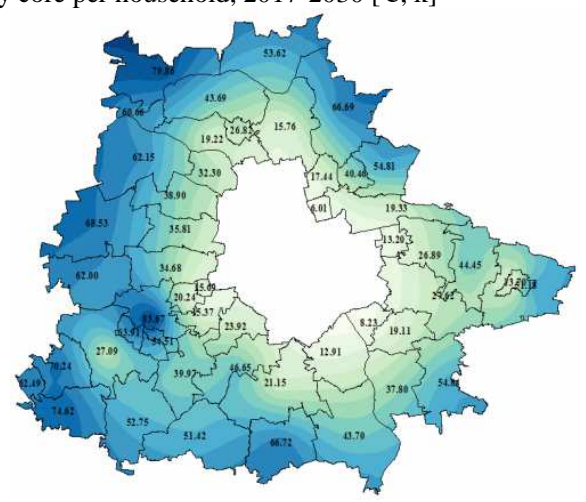

Fig. 6. The projection of direct financial losses and the value of lost time due to commuting to and from the city core per one household, 2017-2030 $[€, \mathrm{k}]$

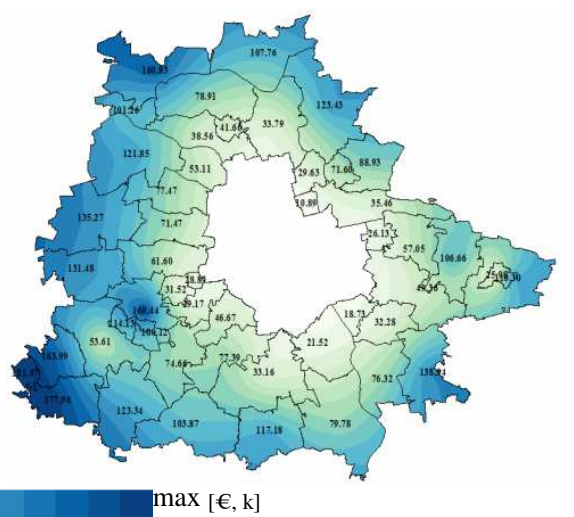




\section{WROCŁAW}

Fig. 1. The direct annual financial losses due to commuting to and from the city core per household $[€, \mathrm{k}]$

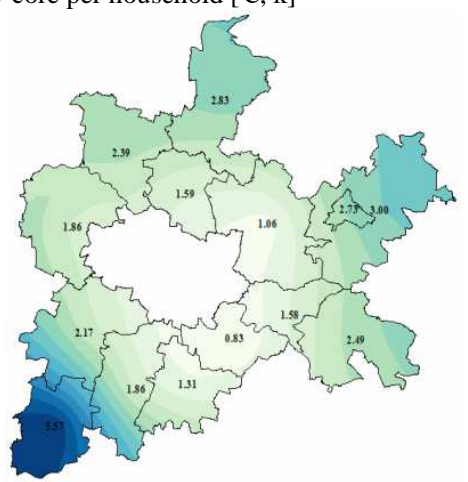

Fig. 3. The annual value of lost time due to commuting to and from the city core per household $[€, \mathrm{k}]$

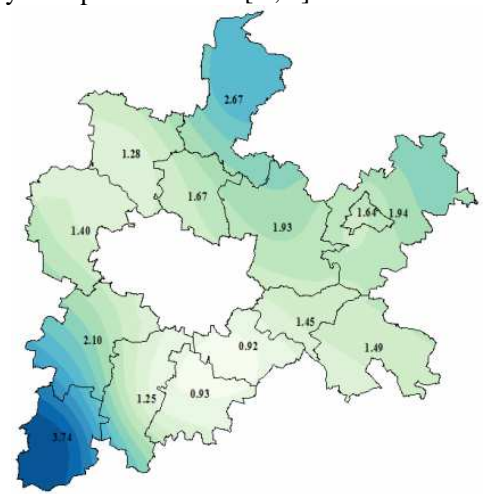

Fig. 5. The direct annual financial losses and the value of lost time due to commuting to and from the city core per household $[€, \mathrm{k}]$

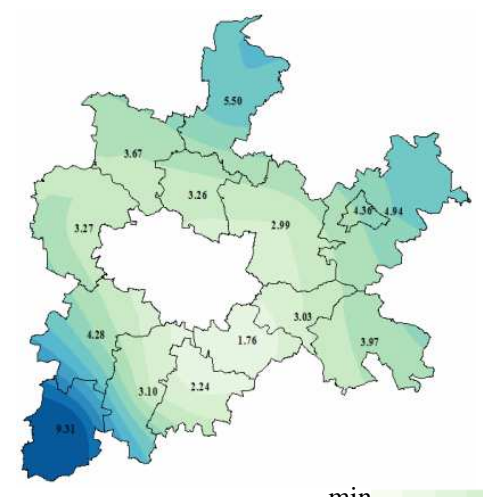

$\min$
Fig. 2. The projection of the direct financial losses due to commuting to and from the city core per household, 2017-2030 [€, k]

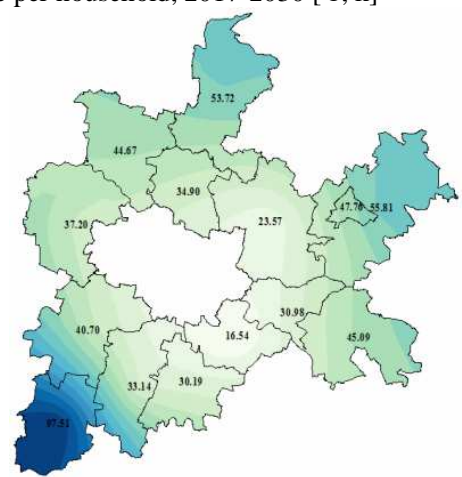

Fig. 4. The projection of the value of lost time due to commuting to and from the city core per household, 2017-2030 [€, k]

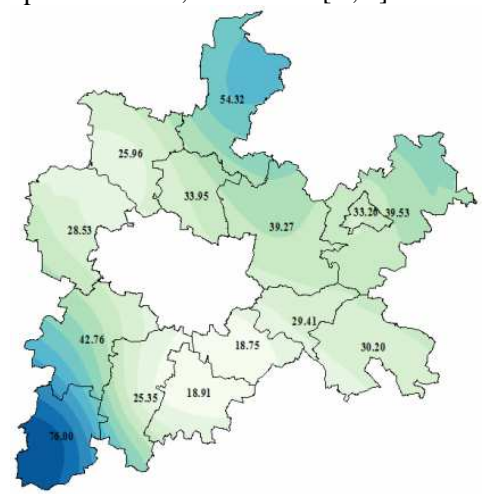

Fig. 6. The projection of direct financial losses and the value of lost time due to commuting to and from the city core per one household, 2017-2030 $[€, \mathrm{k}]$

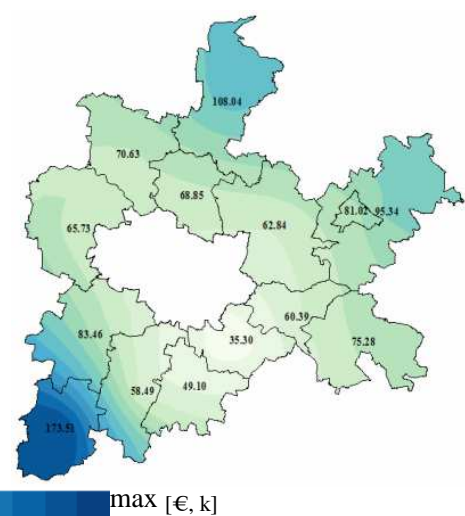




\section{ZIELONA GÓRA}

Fig. 1. The direct annual financial losses due to commuting to and from the city core per household [€, k]

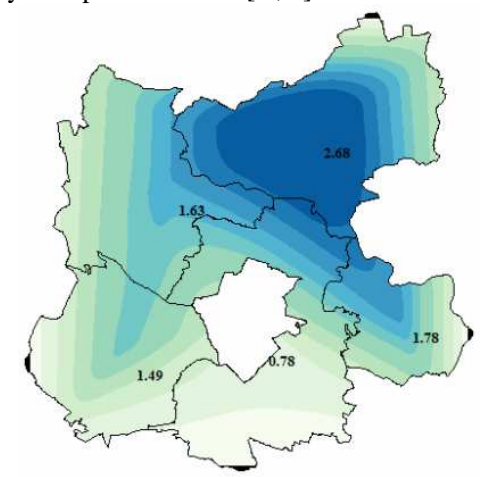

Fig. 3. The annual value of lost time due to commuting to and from the city core per household $[€, \mathrm{k}]$

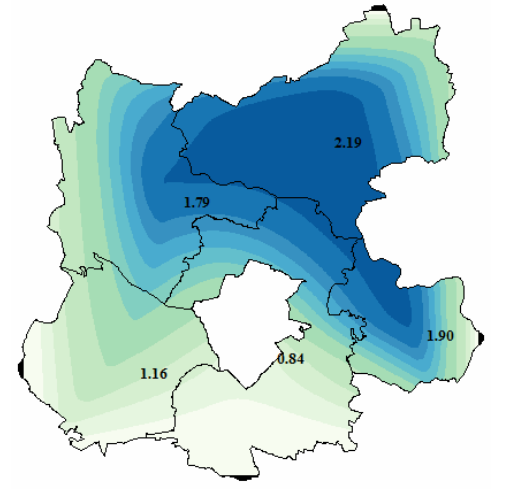

Fig. 5. The direct annual financial losses and the value of lost time due to commuting to and from the city core per household $[€, \mathrm{k}]$

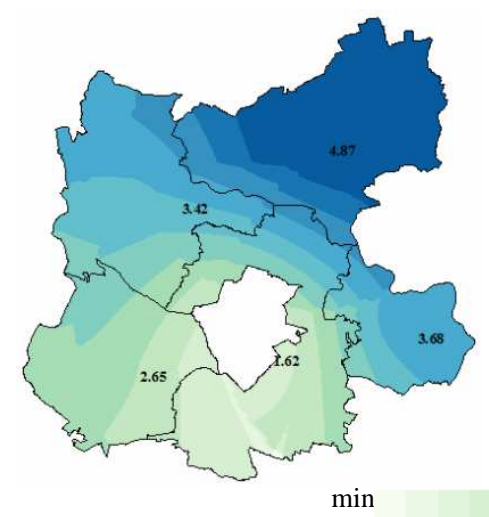

Fig. 2. The projection of the direct financial losses due to commuting to and from the city core per household, 2017-2030 [€, k]

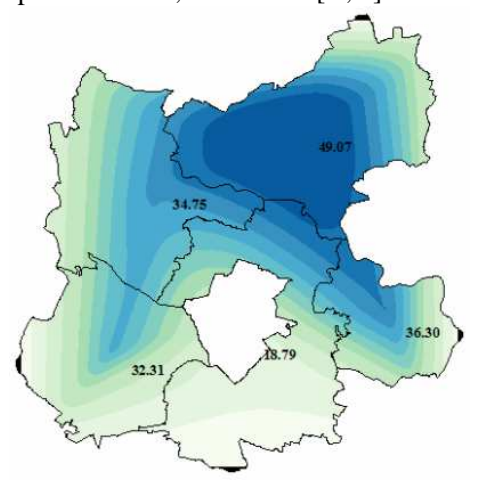

Fig. 4. The projection of the value of lost time due to commuting to and from the city core per household, 2017-2030 [€, k]

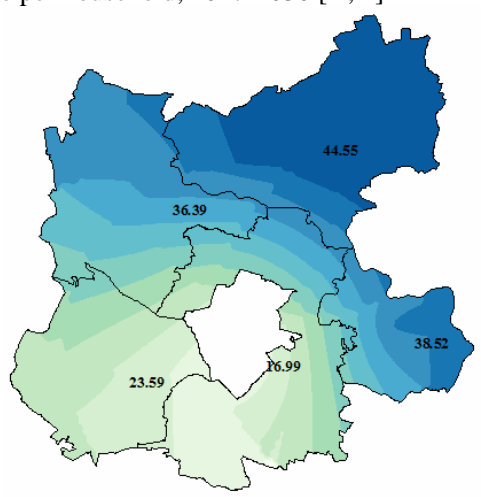

Fig. 6. The projection of direct financial losses and the value of lost time due to commuting to and from the city core per one household, 2017-2030 $[€, \mathrm{k}]$

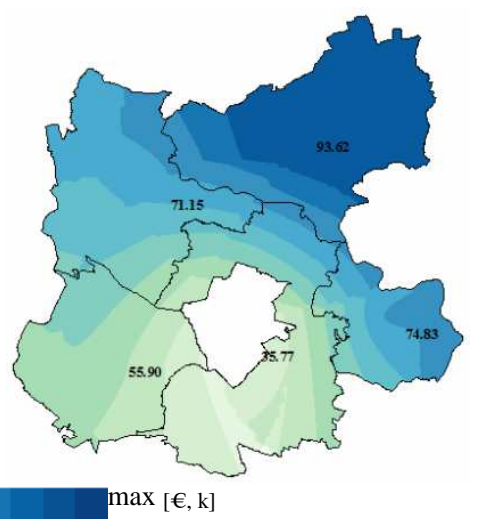

